\title{
Review \\ Transition Metal Dichalcogenides (TMDC)-Based Nanozymes for Biosensing and Therapeutic Applications
}

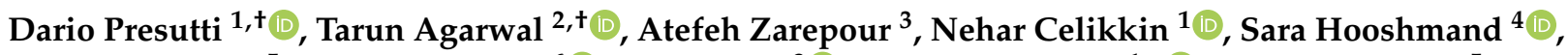

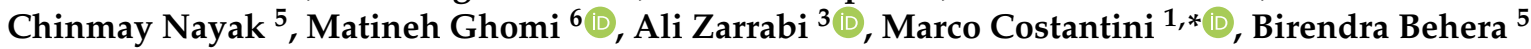 \\ and Tapas Kumar Maiti ${ }^{2, *(1)}$
}

Citation: Presutti, D.; Agarwal, T.;

Zarepour, A.; Celikkin, N.;

Hooshmand, S.; Nayak, C.; Ghomi,

M.; Zarrabi, A.; Costantini, M.;

Behera, B.; et al. Transition Metal

Dichalcogenides (TMDC)-Based

Nanozymes for Biosensing and

Therapeutic Applications. Materials

2022, 15, 337. https://doi.org/

$10.3390 / \mathrm{ma} 15010337$

Academic Editors: Dongdong Wang and Jiawei Liu

Received: 23 November 2021

Accepted: 31 December 2021

Published: 4 January 2022

Publisher's Note: MDPI stays neutral with regard to jurisdictional claims in published maps and institutional affiliations.

Copyright: (C) 2022 by the authors. Licensee MDPI, Basel, Switzerland. This article is an open access article distributed under the terms and conditions of the Creative Commons Attribution (CC BY) license (https:// creativecommons.org/licenses/by/ $4.0 /)$.
1 Institute of Physical Chemistry, Polish Academy of Sciences, 01-224 Warsaw, Poland; dpresutti@ichf.edu.pl (D.P.); ncelikkn@ichf.edu.pl (N.C.)

2 Department of Biotechnology, Indian Institute of Technology, Kharagpur 721302, West Bengal, India; tarun3agarwal5@gmail.com

3 Department of Biomedical Engineering, Faculty of Engineering and Natural Sciences, Istinye University, Istanbul 34396, Turkey; atefeh.zarepour@gmail.com (A.Z.); ali.zarrabi@istinye.edu.tr (A.Z.)

4 Nanotechnology Research and Application Center (SUNUM), Sabanci University, Tuzla, Istanbul 34956, Turkey; s_hooshmand@yahoo.com

5 Department of Biotechnology and Bioinformatics, Sambalpur University, Sambalpur 768019, Odisha, India; chinunayak015@gmail.com (C.N.); bbehera@suniv.ac.in (B.B.)

6 Chemistry Department, Faculty of Science, Shahid Chamran University of Ahvaz, Ahvaz 61537-53843, Iran; ma_gh@rocketmail.com

* Correspondence: mcostantini@ichf.edu.pl (M.C.); maititapask@gmail.com (T.K.M.)

+ These authors contributed equally to this work.

\begin{abstract}
Nanozymes, a type of nanomaterial with enzyme-like properties, are a promising alternative to natural enzymes. In particular, transition metal dichalcogenides (TMDCs, with the general formula $\mathrm{MX}_{2}$, where $\mathrm{M}$ represents a transition metal and $\mathrm{X}$ is a chalcogen element)-based nanozymes have demonstrated exceptional potential in the healthcare and diagnostic sectors. TMDCs have different enzymatic properties due to their unique nano-architecture, high surface area, and semiconducting properties with tunable band gaps. Furthermore, the compatibility of TMDCs with various chemical or physical modification strategies provide a simple and scalable way to engineer and control their enzymatic activity. Here, we discuss recent advances made with TMDC-based nanozymes for biosensing and therapeutic applications. We also discuss their synthesis strategies, various enzymatic properties, current challenges, and the outlook for future developments in this field.
\end{abstract}

Keywords: nanozymes; transition metal dichalcogenides; biosensing; anticancer; antimicrobial; cytoprotection

\section{Introduction}

Recent years have witnessed unprecedented advances in scientific research and technological applications, especially in the field of nanotechnology [1-3]. A recent example of how nanotechnologies can positively impact our lives is their role in fighting COVID-19 global outbreak, where mRNA vaccines have been made using a nanotechnology-assisted RNA delivery approach. Therefore, it is ever more evident that nanotechnologies are advancing rapidly, and nanomaterials are becoming an important pillar of biomedical research [4].

From a healthcare point of view, there is increasing hopefulness that nanomaterials will bring significant advances both in the treatment and diagnosis of diseases. Such ambitious goals have inspired researchers to develop new nano-platforms capable of performing both operations at the same time. This has led to the establishment of a new multi-disciplinary research domain known as theranostics. Examples of theranostic nanomaterials are ironbased metal oxide magnetic nanocrystals, MXene, black phosphorus (BP), graphene oxide 
(GO), manganese dioxide $\left(\mathrm{MnO}_{2}\right)$, and palladium (Pd) [5,6]. In addition to those, an emerging class of materials with theranostic potential is represented by nanozymes (NZs).

Nanozymes (NZs) — a class of nanomaterials exhibiting enzyme-like properties and activities-have been tested for a variety of biomedical applications and are promising alternatives to natural enzymes. These abilities are linked to their inherent nanostructures, which mimic natural enzyme active site or charge/electron transfer [7-9]. The growing interest in NZs is also justified by the fact that these nanomaterials can be easily synthesized and functionalized at a low cost, and their catalytic activities can be tuned without compromising their stability. Furthermore, when compared to natural enzymes or traditional organic enzymes, NZs have a long half-life and are simple to store/manage. NZs with peroxidase (POD), oxidase (OD), catalase (CAT), or superoxide dismutase (SOD)-like activities are the most studied and frequently used for one or more applications, including biological sensing, molecular detection, environmental management, immunoassays, and theranostic applications $[8,10,11]$.

From the material perspective, zero-dimensional (0D) nanomaterials-based on metal, bimetallic compounds, metal oxides, and metal chalcogenides-were the first NZs to be studied [12]. Despite many advantages, 0D NZs suffer from some limitations, including considerable toxicity, low catalytic activity, and the steric hindrance, which impairs the full enzymatic mimicry. Therefore, researchers have developed new strategies to fabricate two-dimensional (2D) nanomaterials [13]. The two most distinguishing features of 2D nanomaterials are-(i) the lateral dimensions, which are often one or several orders of magnitude larger than their thickness and (ii) the numerous reservoirs and abundant anchoring sites present on their surface to load and deliver therapeutic agents [13]. These materials may exist as nanosheets, nanoribbons, nanoplates, and nanowalls [14]. The primary 2D nanomaterials are transition metal dichalcogenides (TMDCs), transition metal oxides (TMOs), metal carbides/nitrides (MXenes), graphitic carbon nitride $\left(\mathrm{g}-\mathrm{C}_{3} \mathrm{~N}_{4}\right)$, hexagonal boron nitride (h-BN), and metal-organic frameworks (MOFs) [13]. TMDCs-with the general formula $\mathrm{MX}_{2}$, where $\mathrm{M}$ represents a transition metal and $\mathrm{X}$ is a chalcogen element-have shown exceptional potential in biomedical applications such as biosensing, tissue engineering, bioimaging, and anticancer therapy $[13,15,16]$. Their unique nano-architecture, high surface area coupled with their unique semiconducting properties with tunable band gaps, impart them different enzymatic properties. Furthermore, the compatibility of these materials with various chemical or physical modification strategies provides an easily scalable method of engineering and controlling their enzymatic performances.

Based on the recent trends and achievements, in this review, we aim at providing a state-of-the-art overview on TMDCs-based NZs with a particular emphasis on biosensing and therapeutic applications.

\section{TMDC Nanozyme: Synthesis, Enzymatic Activities, Regulatory Factors}

TMDC structure comprises of three layers: a central core composed of transition metal atoms (mostly Mo or $\mathrm{W}$ ) embedded between the top and bottom layers of chalcogen (S or Se). In particular, they exhibit strong in-plane covalent bonds and weak out-of-plane van der Waals forces.

This type of structural feature donates specific properties to TMDCs, for instance, the intercalation of metal atoms between the two chalcogen layers can modify and improve their optical properties. Furthermore, these intercalating agents can boost the superconductivity features of TMDCs, reaching an unprecedented collective electronic phenomenon, impossible to achieve without their use. In other words, the addition of metal atoms induces structural changes that increase the distances between the two chalcogen layers that, in turn, enhance the superconductivity capability. However, this feature could also be achieved via (i) electrostatic or chemical doping or (ii) utilizing pressure $[17,18]$. TDMCs can show different structural conformations due to the different spherical coordination of the transition metal atoms. Among them, octahedral (1T) and trigonal prismatic (2H and 3R) are the most common polymorph (Figure 1) [19]. 

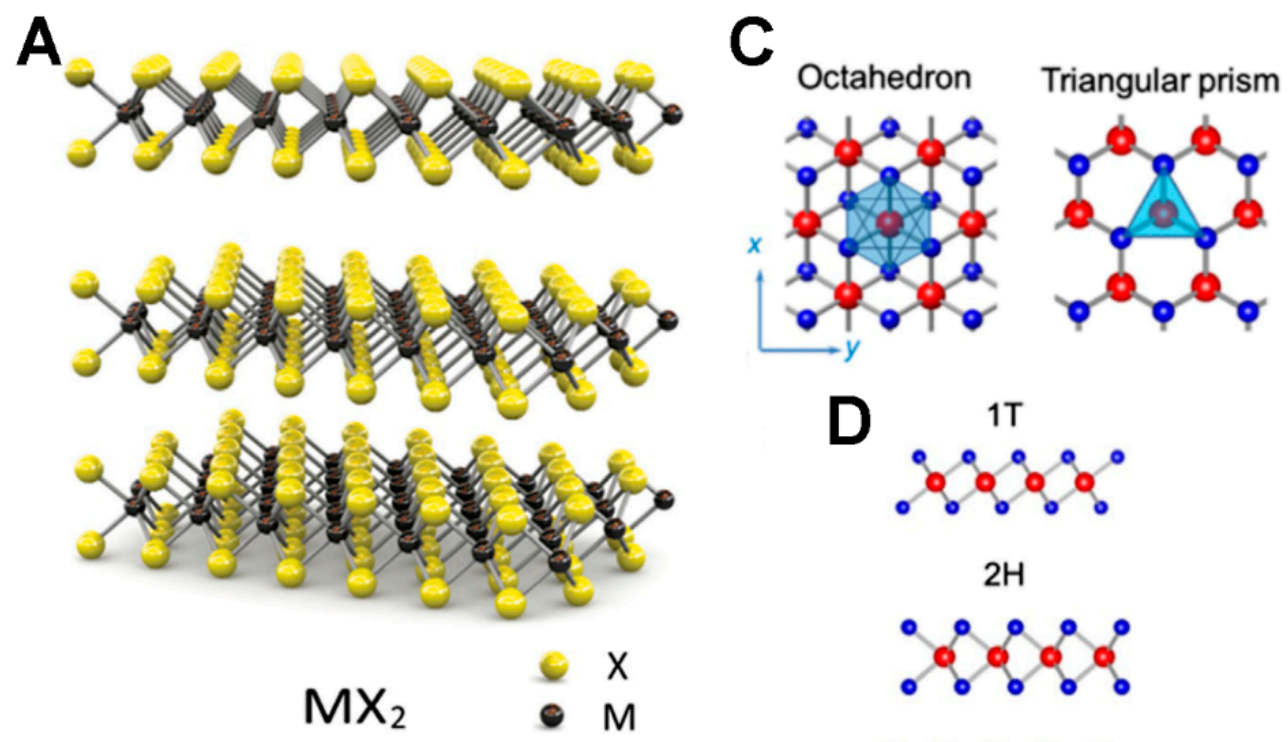

$2 \mathrm{H}$
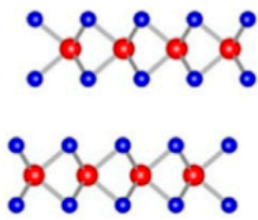

$\mathbf{B}$
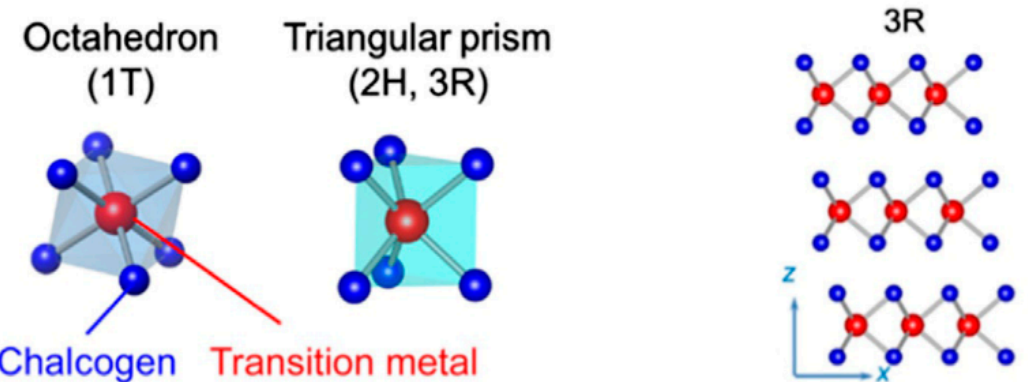

Figure 1. Schematic of (A) 3D-structure of TMDCs, (B) Octahedron and triangular coordination of TMDCs, and (C) top view and (D) side view of common forms of octahedron and triangular poly type. Adapted with permission from Ref. [19]. Copyright 2019 Elsevier.

Depending on the synthesis method, TMDCs show different colloidal proprieties, producing materials with various levels of water stability. To increase it, TMDCs with low water stability could be treated with biocompatible polymers, using covalent functionalization or physical adsorption methods [20,21].

This ultrathin atomic layer structure confers various other interesting features, including enzymatic properties [15]. Remarkably, it is well established that morphology, shape, size, and surface charge of TMDC NZs could affect their enzyme-like activity. For example, the increase of the size can enhance the rate of electrons transfer, modulating the catalytic activity of TMDC NZs. In the same way, the surface charge can also impact the rate of electrons transfer. For instance, TMDC NZs with negative charges favor the electrons transfer when exposed to substrates that show positive charges on their surface [22]. This section, we would elaborate over the aspects of synthesis, different enzymatic activities, and various factors regulating the activities of TMDC NZs.

\subsection{Methods for the Synthesis of TMDC NZs}

Recently, significant progress has been made in the synthesis of TMDCs nanomaterials using bottom-up (chemical vapor deposition, physical vapor deposition, and hydro/solvothermal methods) and top-down (mechanical exfoliation, solvent exfoliation, and ion-intercalation exfoliation) processes [15]. These methods are based on the use of a diverse set of synthetic precursors and ligands, yielding TMDCs with diverse features, 
shapes, phases, and applications. However, our discussion here will be limited to the synthesis methods used to prepare TMDC NZs, along with some relevant examples.

\subsubsection{Hydro/Solvothermal Method}

Hydrothermal or solvothermal synthesis is commonly regarded as the synthesis by chemical reactions of substances in a sealed and heated aqueous solution or organic solvent at high temperatures $\left(100-1000{ }^{\circ} \mathrm{C}\right)$ and associated high pressures $(1-100 \mathrm{MPa})$. Notably, the solvent type and composition can critically affect the geometrical aspects of the synthesized TMDC nanomaterials, highlighting the methods' plasticity [23]. Hence, the hydro/solvothermal method represent a commonly used strategy for TMDCs synthesis and functionalization. The studies conducted by Fan et al. [24] and Zhan et al. [25] pioneered the route for hydro/solvothermal methods and the production of ultrathin nanoscale TMDCs [26].

To date, the syntheses of POD-like NZs have been conducted through hydrothermal or solvothermal synthesis by different groups using various reducing agents or different reaction media to alter reaction mechanisms and kinetics, attain special conformations, structures, condensed states, and particular morphologies. For instance, sodium salt of molybdenum $\left(\mathrm{Na}_{2} \mathrm{MoO}_{4}\right)$ in aqueous media with L-cysteine was used to attain $\mathrm{MoS}_{2}$ nanosheet with POD-like activity. The reaction took place at $200{ }^{\circ} \mathrm{C}$ for $36 \mathrm{~h}$ and L-cysteine acted as a sulfide source as well as a reducing agent [27].

Despite the ease of hydrothermal reactions, the variety of organic solvents with different characteristics, such as boiling point and polarity, offers additional room for new and enhanced synthesis techniques. In solvothermal synthesis, the organic solvent not only supplies a reaction medium but also dissolves or partially dissolves the reactants to form a solvent-reactant complex, affecting the chemical reaction rate. For instance, $\mathrm{MoSe}_{2}$ particles with POD-like activity have been synthesized through the microwave-assisted solvothermal reaction in N-methyl-2-pyrrolidone in less than an hour. Interestingly, the study evaluated the effect of the reaction temperature on $\mathrm{MoSe}_{2}$ phases, i.e., metal $1 \mathrm{~T}$ phase and semiconductor $2 \mathrm{H}$ phase. With a decrease in synthesis temperatures $(240,220$, and $\left.180{ }^{\circ} \mathrm{C}\right), \mathrm{MoSe}_{2}$ phases transitioned from $2 \mathrm{H}$ phase to $1 \mathrm{~T}$ phase. $2 \mathrm{H}-\mathrm{MoSe}_{2}$ exhibited good crystallinity and semiconductor properties, whereas $1 \mathrm{~T}$ structure had a certain degree of disorder and metallic properties. Notably, 1T structures possessed higher POD-like activity than $2 \mathrm{H}-\mathrm{MoS}_{2}$ [28]. Tungsten disulfide $\left(\mathrm{WS}_{2}\right)$ quantum dots with POD-like activity were synthesized by solvothermal process in dimethylformamide (DMF). Despite the fact that the reaction lasts for $6 \mathrm{~h}$, it occurs at lower temperatures $\left(140{ }^{\circ} \mathrm{C}\right)$ [29].

\subsubsection{Chemical Vapor Deposition (CVD) and Physical Vapor Deposition (PVD)}

CVD is a chemical process that allows the generation of nanocoating or nanomaterials employing gas/steam reactions. This approach consists in injecting two or more gaseous raw materials into a reaction chamber to enable their interaction and deposit a new material on a molten substrate or a heated solid. It has widely been used to fabricate TMDCs on a large scale, with tunable thickness, such as $\mathrm{MoS}_{2}, \mathrm{MoSe}_{2}, \mathrm{WS}_{2}, \mathrm{ReS}_{2}$ nanosheets, and some heterostructures. Precisely, during CVD preparation, transition metal oxides (such as $\mathrm{MoO}_{3}$ or $\mathrm{WO}_{3}$ ) are placed with chalcogenide elemental powders (for example, sulfur powder or selenium powder) in a furnace. Exposure to high temperature $\left(700-800^{\circ} \mathrm{C}\right)$ causes the chalcogenide powder to form steam, which then reacts with transition metal oxides to generate thin TMDC films on melted $\mathrm{SiO}_{2}$ or sapphire substrates [30,31]. Recently, Gao and colleagues have synthesized a monolayer of $\mathrm{WSe}_{2}$ on $\mathrm{Au}$ foil, at the millimeter scale, within $30 \mathrm{~s}$, suggesting that the ultrafast method proposed, in which it is possible to modulate the growth time, is useful to control the crystal size if precursors are continuously provided [32]. Remarkably, Appel and colleagues have investigated the biocompatibility of mechanically exfoliated and CVD-grown pristine 2D TMDCs $\mathrm{MoS}_{2}$ and $\mathrm{WS}_{2}$. The authors did not report any toxic effects on mammalian and bacterial cells. Furthermore, these materials did not alter the level of ROS, suggesting that they can be useful for fabricating medical 
devices [33]. Chen and co-authors analyzed the biocompatibility of $\mathrm{MoS}_{2}$ biosensors synthesized via CVD. Using both in vitro cell assays and in vivo immunological experiments, the research team demonstrated that $\mathrm{MoS}_{2}$ is a biocompatible semiconductor. Interestingly, the authors have also investigated the stability of polycrystalline $\mathrm{MoS}_{2}$ monolayer (grain size $\sim 200 \mathrm{~nm}$ ) in the water phase, observing that a complete degradation can be achieved in approximately two months. This study highlighted the capability to integrate TMDC NZs into bioabsorbable and water-soluble electronic platforms to be used in biomedical implants [34].

Apart from CVD, several PVD approaches have also been proposed, including vacuum evaporation, sputtering, arc plasma, ion plating, and molecular beam epitaxy (MBE) for TMDC synthesis. All these PVD methods share common features. In particular, using an intense energy input, it is possible to generate monolayer alloys by direct vaporization of the end TMDCs powder (such as $\mathrm{MoS}_{2}$ or $\mathrm{MoSe}_{2}$ ). Successively, at a lower temperature, the vapor can condense on a substrate's surface under ultra-high vacuum condition $\left(1 \times 10^{-8}\right.$ Torr $)$ or in the presence of ultra-high purity gas. Since TMDCs do not contain dangling bonds and do not require to satisfy lattice matching conditions, the MBE approach is a suitable tool for their synthesis. Therefore, MBE represents the most used PVD production method $[15,35]$.

\subsubsection{Exfoliation Method}

As a top-down strategy, this method involves stripping TMDC bulks to generate few-layered or monolayered structures. Depending upon the approach opted, this method can further be classified as solvent-based exfoliation and mechanical exfoliation [15,36].

On one hand, the solvent-based exfoliation method entails dispersing TMDC bulk materials in an appropriate solvent before exposing them to ultrasound. The solvent properties, in conjunction with sonication-induced micro/nano-bubbles, separate TMDC monolayers by increasing the distance between the layers and decreasing van der Waals forces. This method offers exfoliation and functionalization of TMDC materials simultaneously. Notably, the selection of an appropriate solvent during the process is critical to prevent the clustering and suspension maintenance of the exfoliated material [37]. Therefore, Hildebrand and Hansen parameters must be considered when choosing a solvent. Mixtures of isopropyl alcohol (IPA)/water, acetone/water, or Tetrahydrofuran/water are frequently preferred. Furthermore, the type of TMDC material also influences the solvent/water ratio selection. According to Shen and colleagues. the proportion of IPA/water for $\mathrm{WS}_{2}$ and $\mathrm{MoSe}_{2}$ monolayers should be 1:1, while for $\mathrm{MoS}_{2}$, it should be 7:3 [37]. As an alternative solvent mixture, ethanol/water mixture was used to attain few-layered $\mathrm{MoSe}_{2}$ nanosheets. The commercial $\mathrm{MoSe}_{2}$ powder was dispersed in a $45 \mathrm{vol} \%$ ethanol/water mixture under ultrasonication $\left(80 \%\right.$ amplitude) for $8 \mathrm{~h}$ at $10{ }^{\circ} \mathrm{C}$. Indeed, the atomic force microscopy (AFM) and transmission electron microscopy (TEM) analysis clearly indicated an efficient exfoliation of the bulk $\mathrm{MoSe}_{2}$ powder [38]. An ethanol/water mixture was also used to obtain $\mathrm{WSe}_{2}$ nanosheets; however, ethanol concentration was reduced to $12 \%$. Similar to the previous studies, the exfoliation of the bulk WSe $\mathrm{W}_{2}$ into $\mathrm{WSe}_{2}$ nanosheets was demonstrated with TEM, X-ray powder diffraction (XRD), and AFM analysis. Moreover, regarding its enzymatic activity, $\mathrm{WSe}_{2}$ nanosheets show higher POD-like activity than bulk $\mathrm{WSe}_{2}$ [39].

Mechanical exfoliation method can also be used, wherein processes such as grinding, ball milling, and scotch-tape causes exfoliation of layers from bulk TMDC crystal $[15,36]$. In the scotch-tape method, TMDC bulk material is affixed to adhesive tape and foldedunfolded multiple times to allow the material's thinning. On the other hand, grinding or ball milling methods are fragmented and stripped by friction and collision. Despite their ease of use and low cost, these methods have yet to be used to prepare TMDC-NZs. However, in a recent study, the mechanical grinding process in the presence of ionic liquid (1-butyl-3-methylimidazolium hexafluorophosphate) and chitosan was used to prepare chitosan-functionalized $\mathrm{MoSe}_{2}$ nanosheets with POD-like activity [40]. 
Similarly, ion-intercalation exfoliation (IE) is achieved through the insertion of ion impurities between the layers of TMDC crystal bulks. This increases interlayer space by overcoming van der Waals forces. Due to their high reduction potential and mobility, lithium ion-based intercalants, such as n-butyllithium in hexane, are the most commonly used in this method. The TMDC crystals are hydrolyzed and ultrasonicated to promote efficient intercalation of Li-ions and stacking of the material [24]. As an alternative to the classic IE method, a considerably faster and flexible electrochemical approach can be employed. In this, an electrical voltage is applied between a lithium foil (anode) and a TMDC crystal submerged in an electrolyte solution in the procedure (cathode). As a result, lithium enters between the TMDC layers, and the nanosheets are exfoliated by ultrasonication [41].

\subsection{Synthesis of TMDC Hybrids with Enzymatic Activity}

\subsubsection{Doped TMDC NZs}

Doping is an effective approach to manipulate the overall performance of TMDC-NZs, resulting from the change in material's electronic structure. The doping approach often involves the substitution of host atoms with anionic or cationic impurity atoms. In anion substitution, host chalcogenide atoms are replaced with non-metal dopant, whereas in the cationic substitution, impurity atoms replace the host transition metal atoms [36]. It is often observed that the doped TMDC-NZ exhibit better enzymatic activity as compared to the non-doped counterparts as a result of the shifts in the Fermi levels. For instance, a two-step gas expansion and exfoliation strategy was used to obtain nitrogen-doped $\mathrm{MoS}_{2}$ $\left(\mathrm{N}-\mathrm{MoS}_{2}\right)$ and nitrogen-doped $\mathrm{WS}_{2}\left(\mathrm{~N}-\mathrm{WS}_{2}\right)$ nanosheets. Briefly, the interlayers of bulk $\mathrm{MoS}_{2}$ and $\mathrm{WS}_{2}$ were expanded with urea molecules in water. Urea which decomposed to $\mathrm{NH}_{3}$ during the hydrothermal process and sulfur atoms of TMDCs were partly replaced by $\mathrm{N}$ atoms to achieve $\mathrm{N}$ doping. The study also revealed that the doping extent was highly dependent on the amount of urea used in the process [42]. Alternatively, plasma treatment, with the merits of low energy consumption and chemical waste-free yield, can also be used for doping. In a recent study, hydrothermally synthesized $\mathrm{MoS}_{2}$ nanosheets were exposed to nitrogen plasma to generate N-MoS 2 NZs that have better POD-like activity and stability than non-doped counterparts [43].

Notably, in relevance to TMDC NZs, cationic doping and its effects on enzymatic performance have still not been fully evaluated and thus, present a scope for further research and development. However, it is well established that tungsten doping on MoTMDCs and vice versa are suitable cation substitution processes to handle the optical properties [44]. In the same line, rhenium (Re) and Niobium $(\mathrm{Nb})$ have been used as n- or p-type dopants, respectively, to manipulate the Fermi level of $\mathrm{MoS}_{2}[45,46]$.

\subsubsection{Functionalized TMDC NZs}

Despite TMDCs show good biocompatibility, different modifications (physical or chemical) are often needed to further tune their medical applicability. These modifications often affect colloidal stability, dispersibility, selectivity, and sensitivity of TMDC NZs [11]. In particular, functionalization can change the $\mathrm{pH}$ and the temperature at which the TMDC NZs show their activity. Dextran-functionalized $\mathrm{MoSe}_{2}\left(\mathrm{dex}-\mathrm{MoSe}_{2}\right)$ was synthesized by addition of dextran to the solution containing bulk $\mathrm{MoS}_{2}$, followed by ultrasound-mediated exfoliation process. Dextran formed multivalent hydrogen bonding with exfoliated $\mathrm{MoS}_{2}$ nanosheets, thereby stabilizing them. These NZs showed POD-like catalytic activity under broad $\mathrm{pH}$ conditions, including $\mathrm{pH}$ 7.4, which makes it suitable for biological diagnostic applications. Besides, the study also revealed that the catalytic activity of dex-MoSe was significantly higher than PEG-MoSe ${ }_{2}$ or chitosan-MoSe $e_{2}$, produced following the same protocol [37]. Polyvinylpyrrolidone (PVP) was added to the reaction solution for hydrothermal synthesis of ultra-small $\mathrm{MoS}_{2}$ nanoparticles to obtain biocompatible PODlike catalytic system. This system exhibited catalytic activity and stability up to $35^{\circ} \mathrm{C}$; 
however, a marked decrease in activity was observed above $35^{\circ} \mathrm{C}$. Moreover, a good catalytic activity was observed over a broad $\mathrm{pH}$ range from 3.5 to 6.5 [47].

Functionalization of TMDC NZs with charged polymers also affects the selectivity to substrates. Positively and negatively charged surfactants, i.e., cetyl trimethyl ammonium bromide (CTAB) and sodium dodecyl sulfate (SDS) respectively, were used to modify solvothermally generated $\mathrm{MoS}_{2}$ nanoparticle. The POD-like activity of nanoparticles was obtained to be highly dependent on the surface charge and the highest catalytic activity toward 3,3' 5, $5^{\prime}$-tetramethylbenzidine (TMB; positively-charged) was attained with negatively charged SDS-MoS 2 nanoparticles, primarily due to the high affinity to substrate [48]. In an alternate study, the effect of charge on enzymatic activity and affinity was investigated using positively charged polyethyleneimine (PEI), negatively charged polyacrylic acid (PAA), neutrally charged PVP, and positively/negatively charged cysteine (Cys) to functionalize $\mathrm{MoS}_{2}$ nanoflakes (MoS $2 \mathrm{NFs}$ ). The results indicated Cys-MoS worked well with TMB as well as 2,2'-Azino-bis(3-ethylbenzothiazoline-6-sulfonic acid) diammonium salt (ABTS; negatively-charged) substrates. PAA and PVP modification mildly, while PEI completely blocked the catalytic of NZs [49]. In addition, another study functionalized $\mathrm{WS}_{2}$ nanosheets with hemin (iron protoporphyrin), the active center of the heme-protein family, including cytochromes, peroxidases, myoglobin, and hemoglobin. The hemin $/ \mathrm{WS}_{2}$-NSs has exhibited POD-like catalytic activity at broader $\mathrm{pH}$ and temperature range as compared to HRP. Moreover, a higher activity was observed with hemin $/ \mathrm{WS}_{2}-\mathrm{NSs}$ than hemin itself or $\mathrm{WS}_{2} \mathrm{NSs}$ alone [50].

\subsubsection{TMDC Nanocomposites with Enzymatic Activity}

Besides doping and functionalization, engineering TMDC nanocomposites is also widely studied in order to achieve the optimal enzymatic activity conditions, alter the selectivity and the affinity of TMDC NZs to substrates and creating various nano architectures. For instance, Copper nanowires ( $\mathrm{Cu} \mathrm{NWs)} \mathrm{were} \mathrm{used} \mathrm{as} \mathrm{nucleation} \mathrm{sites} \mathrm{to} \mathrm{generate}$ dense, vertically organized, interconnected $\mathrm{MoS}_{2}$ NSs. The resulting $\mathrm{Cu}$ NW-MoS 2 NSs composite exhibited a rough surface, allowing better bacterial adhesion and improved POD-like activity compared to both bare $\mathrm{Cu}$ NWs and $\mathrm{MoS}_{2}$ NSs [51]. Likewise, Wang and colleagues developed $\mathrm{MoS}_{2} / \mathrm{rGO}$ vertical heterostructures with numerous cracks on crystal structure at the basal surface. The increased area of catalytic sites increased the probability of active edge sites exposure and rough surface for bacteria capture, thus improving the antibacterial performance [52]. As an alternative system, 2D/2D heterojunction of $\mathrm{MoS}_{2}$ with g- $\mathrm{C}_{3} \mathrm{~N}_{4}$ imparted synergistic effects on POD-like activity by efficiently accelerating the electron transport compared to pure g- $\mathrm{C}_{3} \mathrm{~N}_{4}$ nanosheets and $\mathrm{MoS}_{2}$ NSs [53]. Other than $\mathrm{rGO}$ and $\mathrm{C}_{3} \mathrm{~N}_{4}$ nanosheets, implementing AuNPs on $\mathrm{MoS}_{2}$ quantum dots (AuNPs@MoS 2 -QDs) enhanced and stabilized POD-like activity, which was comparable to HRP. Higher Fermi level and the involvement of excess electrons in the conduction band of AuNPs resulted in an easy electron transfer, leading higher catalytic activity of composites [54]. Other than that, algae-like polypyrrole (Ppy)@MoS [55] and flower-like $\mathrm{MoS}_{2} @ \mathrm{MgFe}_{2} \mathrm{O}_{4}$ nano-constructs [56] were also reported with enhanced catalytic activity than their parent counterparts.

New frontiers of TMDC-NZs and biocatalysis are the Single-atom (SA) NZs with isolated active metal centers can be anchored on solid supports. Wang and colleagues prepared SA Co-MoS 2 via assembly of Co nanodiscs on $\mathrm{MoS}_{2}$ nanosheets with relatively higher POD activity as compared to only $\mathrm{MoS}_{2}$ NZ. Interestingly, the authors reported that occurrence of two different mechanisms in the case of nanocomposite that synergistically elevated enzymatic performance. In particular, SA Co reaction center favored electron transfer mechanism, while $\mathrm{MoS}_{2}$ followed Fenton-like mechanism [57]. In the near future, more such SA TMDC NZs systems are certainly expected to be investigated. 


\subsection{Different Enzymatic Activities and Factors Regulating Them}

To date, various nanomaterials, including TMDCs, have been reported to display outstanding catalytic activity towards a specific substrate, often following a Michaelis-Menten catalytic kinetic profile. In terms of enzymology, it is proposed that one NZs-Unit represents the quantity of NZs required to catalyze $1 \mu \mathrm{mol}$ of substrate per minute. Based on the type of catalytic reaction mimicked, NZs can be categorized into several subtypes, including POD-like, OD-like, SOD-like, and CAT-like [13] (Figure 2).

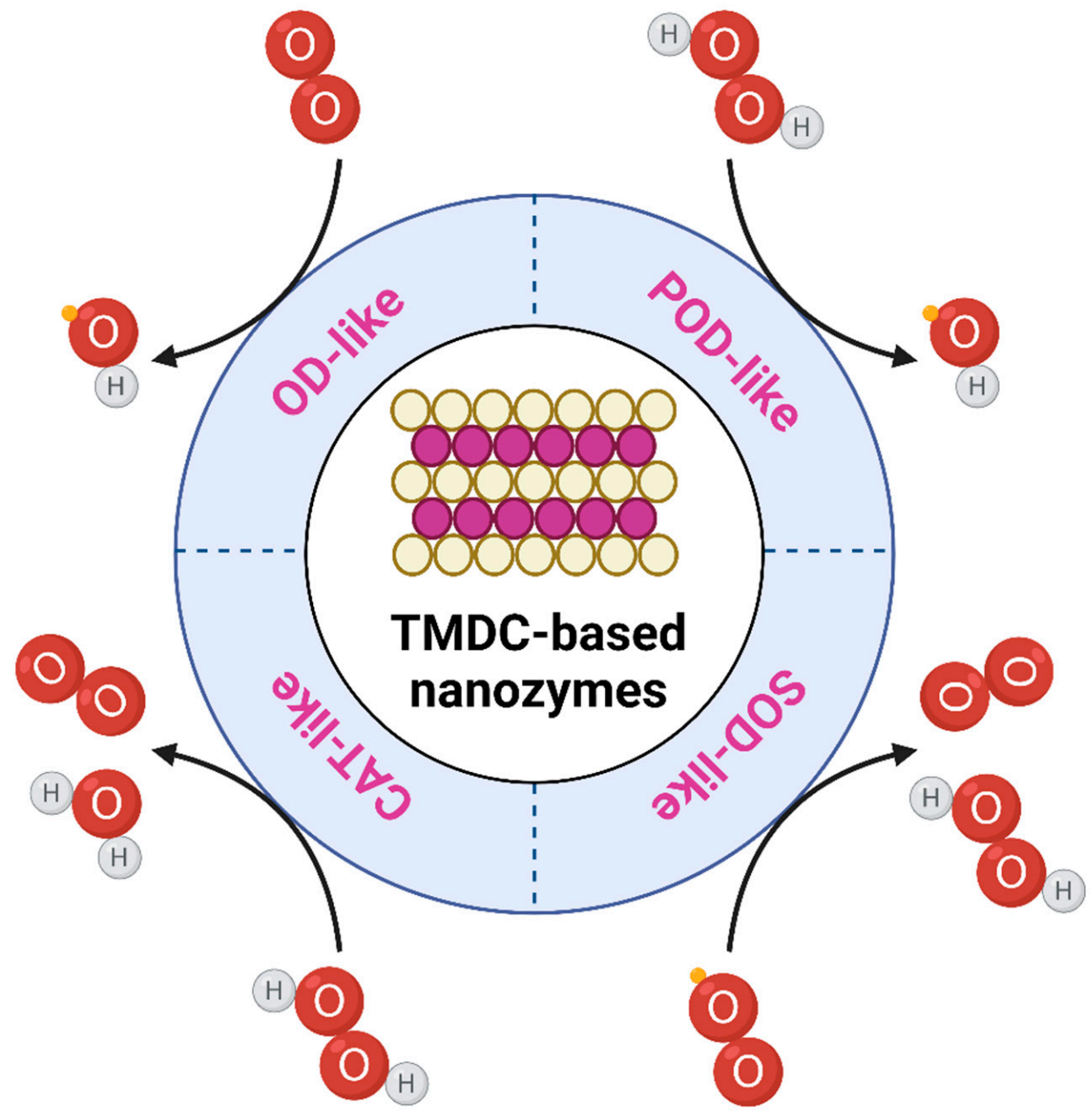

Hydroxyl radical

Figure 2. Different enzymatic activities and their mechanisms followed by TMDC-based NZs.

POD activity of TMDC NZs represents the catalysis of peroxides (like hydrogen peroxide $\left(\mathrm{H}_{2} \mathrm{O}_{2}\right)$ ) and results into the oxidation of the substrates, mainly via the production of reactive hydroxyl radical $\left({ }^{\bullet} \mathrm{OH}\right)$. TMDC NZs with OD activity, in contrast, utilizes oxygen $\left(\mathrm{O}_{2}\right)$ as a substrate to generate ${ }^{\bullet} \mathrm{OH}$, thereby avoiding the usage of unstable and potentially damaging $\mathrm{H}_{2} \mathrm{O}_{2}$. Biosensing (through the utilization of different chromogenic substrates such as TMB, ABTS, and O-phenylenediamine dihydrochloride (OPD) as well as antibacterial and anticancer therapies can all benefit from TMDC NZs with POD/OD-like activity (via oxidative damage to cellular components) [38,58,59]. SOD and CAT mimicking TMDC NZs, on the other hand, have antioxidant properties and play an important role 
in ROS management. In particular, SOD activity entails disproportionation of ${ }^{\bullet} \mathrm{O}_{2}{ }^{-}$into $\mathrm{O}_{2}$ and $\mathrm{H}_{2} \mathrm{O}_{2}$, whereas dismutation of $\mathrm{H}_{2} \mathrm{O}_{2}$ into $\mathrm{O}_{2}$ and $\mathrm{H}_{2} \mathrm{O}$ occurs in the case of CAT activity. As a result, these TMDC NZs could be used to treat inflammatory diseases like osteoarthritis and neurodegenerative disorders [13].

The sensitivity of NZs determines their potential applicability. The number of active sites/centers and the conductivity of TMDCs, in particular, have an impact on their enzymatic activity. Researchers have made significant efforts to improve the catalytic performance of TMDC NZs. So far, the production of TMDC NZs with, paradoxically, structural defects to create extra edge sites and treatment with different functional groups-cooperatively anchored on their surface-are the most popular ways for promoting enzyme-mimicking activity. Apart from that, other extrinsic factors, such as $\mathrm{pH}$, temperature, exposure to light, and the presence/absence of a particular component (like certain metal ions), can also modulate their performance. For instance, the relative peroxidase activity of $\mathrm{WS}_{2}$ quantum dots reduced by $40 \%$ from $\mathrm{pH} 2.2$ to $\mathrm{pH} 5-7$, but increased from 20 to $100 \%$ when the temperature was raised from $25{ }^{\circ} \mathrm{C}$ to $65^{\circ} \mathrm{C}$ (via exposure to $808 \mathrm{~nm}$ NIR laser irradiation) [60]. In another work, $\mathrm{MoS}_{2}$ nanosheets were found to have good POD activity over a wide $\mathrm{pH}$ range of $2-7.5$, but decreased catalytic activity at temperatures $>40{ }^{\circ} \mathrm{C}$ [61]. Chitosan modified $\mathrm{MoSe}_{2}$ showed optimal POD activity at $\mathrm{pH} 3.5$ and $55^{\circ} \mathrm{C}$ temperature; higher $\mathrm{pH}$ or lower temperatures were linked with lower activity [28]. The presence of $\mathrm{Fe}^{2+}$ ion increased POD activity of $\mathrm{WS}_{2} \mathrm{NZs}$ [62], whereas the presence of $\mathrm{Pb}^{2+}$ ion hindered it [63].

\section{TMDC Nanozymes: Application Perspective}

In this section, applications of TMDC NZs in different fields-starting from biosensing to different treatment fields like antibacterial, anti-inflammation activity and cancer therapy-are discussed in more details. Figure 3 summarizes the mechanism of action of TMDC NZs to exert various therapeutic and diagnostic effects.

\subsection{Biosensing Applications}

A biosensor is an analytical system that can detect a specific biological analyte and translate presence and/or concentration information into analytical data, such as electrical, optical, and thermal signals, using a simple, low-cost, and time-effective operation $[13,64,65]$. With the advent of nanotechnology, NZ biosensors, including TMDC-based, have witnessed enormous applicability in biomedical domain, particularly diagnostics, due to their intrinsic enzymatic capabilities [13]. To date, TMDC NZs have been used to detect a variety of biochemical analytes, including tiny biomolecules (such as glucose, cholesterol, glutathione (GSH), and cysteine) as well as macromolecules (e.g., proteins).

TMDC NZ-based biosensing strategies primarily take advantage of their POD-like activity, in which they can oxidize chromogenic substrates (such as TMB, ABTS, and OPD) in the presence of $\mathrm{H}_{2} \mathrm{O}_{2}$ to produce colored products that can be measured colorimetrically $[43,55,66]$. This NZ-based $\mathrm{H}_{2} \mathrm{O}_{2}$ biosensing is frequently coupled with analyte-specific oxidases such as glucose oxidase (GOx), cholesterol oxidase (ChOx), xanthine oxidase $(\mathrm{XOx})$, and uricase to detect glucose, cholesterol, xanthine, and uric acid, respectively, in biological samples. First, a specific oxidase enzyme metabolizes the bioanalyte in the presence of oxygen to produce a specific acidic product and $\mathrm{H}_{2} \mathrm{O}_{2}$ as a byproduct. This $\mathrm{H}_{2} \mathrm{O}_{2}$ is further sensed colorimetrically by NZs as mentioned above. Notably, within the linear detection range, the intensity of color correlates directly with the amount of bioanalyte present in the samples. The GOx/WS 2 biosensor system, for example, was used to detect glucose with a linear range of $5-300 \mu \mathrm{M}$ and a detection limit of $2.9 \mu \mathrm{M}$ [67]. Similarly, cholesterol was successfully detected at concentrations as low as $15 \mu \mathrm{M}$ using a ChOx/Au nanoparticle-laden $\mathrm{MoS}_{2}$ nanoribbon system [68], whereas uricase/MoS 2 nanoflakes sensor could detect uric acid within a range of $0.5-100 \mu \mathrm{M}$ in human serum samples [69].

On the contrary, the detection regimes for cysteine and glutathione (GSH) differ substantially. The ability of these materials to prevent oxidation of colorimetric substrates 
or revert the oxidized colored product (produced via POD-/OD-like activity of NZs) to its pristine unoxidized form is the basis for their sensing [70]. The color intensity of the reaction mix is inversely proportional to the amount of cysteine or GSH present. Previously, $\mathrm{WS}_{2}$ nanomaterial with POD-like activity was used to estimate GSH levels as low as $0.061 \mathrm{nM}$ and a linear detection range of 0.1-10 nM. GSH levels in human serum samples could be measured easily and without interference from other substances [70]. Similarly, cysteine was quantified using $\mathrm{Hg}^{2+}$ stimulated OD-like activity of $\mathrm{MoS}_{2}$ QDs-Ag NPs in the $1-100 \mu \mathrm{M}$ range [71].
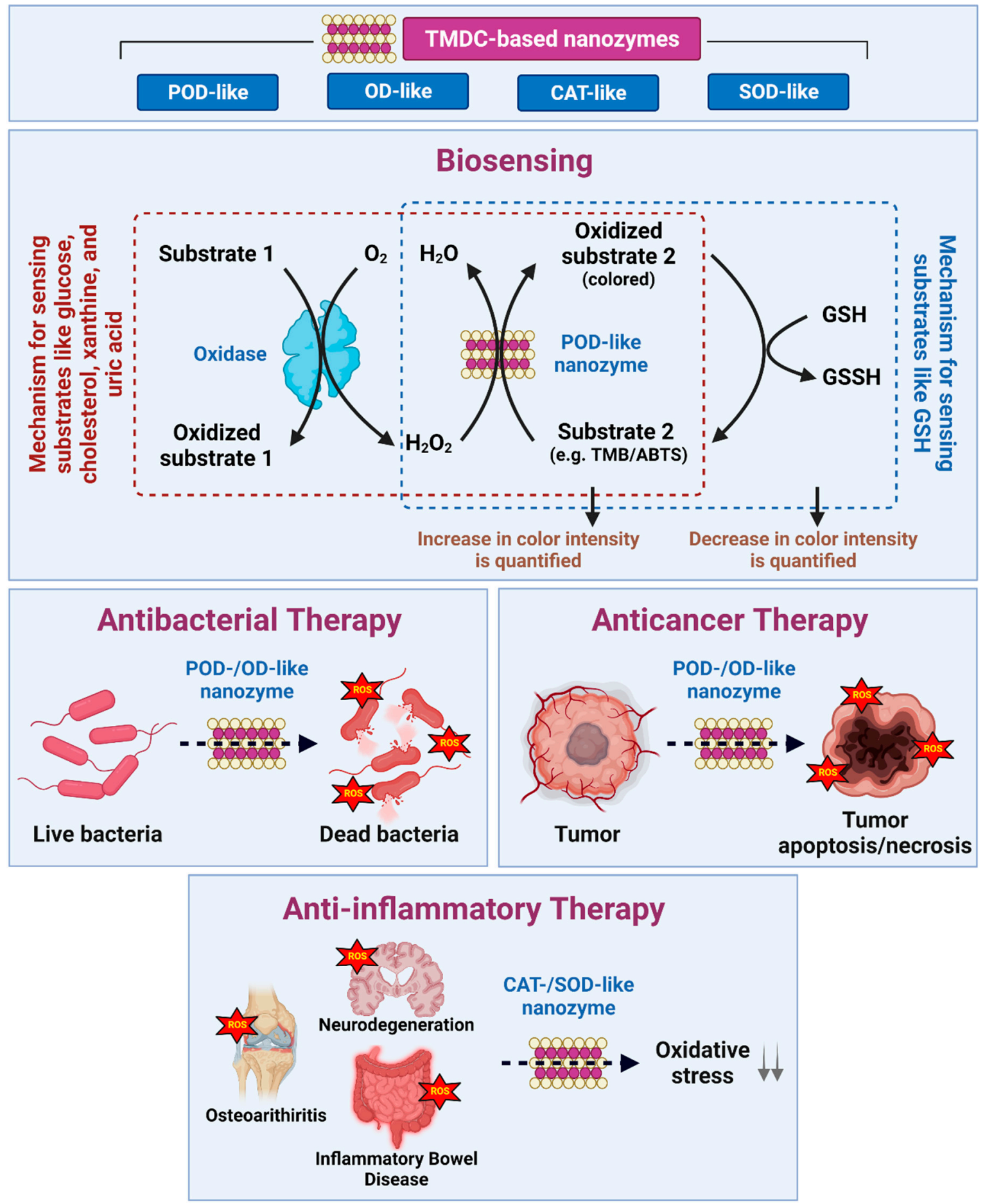

Figure 3. Summary of TMDC-based NZs, their nanozymatic activities, and biomedical applicationsbiosensing, antibacterial, anticancer, and anti-inflammatory therapy. 
TMDC NZs can also be used to detect biomacromolecules, such as proteins, in a simple and label-free manner. To date, protein biosensing has been approached in a variety of ways. For instance, lipase was found to prevent POD-like activity of $\mathrm{MoS}_{2}$, allowing its detection at concentrations as low as $5 \mathrm{nM}$ [72]. Other TMDC NZs-based protein detection strategies utilize nucleic acid aptamer probes due to their target (proteins or other biomolecules) selectivity, chemical stability, and ability to be synthesized in vitro [73]. ssDNA aptamer probe/ $\mathrm{MoS}_{2}$ nanosheet system was used to detect carcinoembryonic antigen (CEA). In comparison to bare $\mathrm{MoS}_{2}$ nanosheets, the POD-like activity of aptamer/MoS 2 was $\sim 4.3$ times higher, enabling greater oxidation of TMB substrate and consequently higher color intensity. However, when the target analyte, CEA, is present, the attached aptamer probe releases from the $\mathrm{MoS}_{2}$ nanosheet's surface and binds with the protein, showing a reduced TMB oxidation. This drop in color intensity can be measured and is inversely proportional to the CEA concentration. Using this method, CEA could be detected in a linear range of 50-1000 ng/mL with the detection limit of $50 \mathrm{ng} / \mathrm{mL}$ [74]. Aptamer-anchored $\mathrm{MoS}_{2} / \mathrm{PtCu}$ nanocomposites with strong OD-like activity were used to detect mucin 1 positive cells with high sensitivity and selectivity. Cells such as MCF-7 and A549, which have mucin 1 overexpression, could be detected even in populations as small as 300 cells. The use of NZs with OD-like activity, as in this case, is often advantageous because it surpasses the use of cytotoxic $\mathrm{H}_{2} \mathrm{O}_{2}$, thus improving the biocompatibility and allowing the biosensor to be used in conjunction with living cells [58]. Besides, protein-specific antibodies [75] or antibody/aptamer probes [76] were also physically/chemically conjugated onto TMDC NZs to detect Salmonella typhimurium-specific surface proteins and human epididymis-specific protein 4 (HE4) proteins, respectively.

Table 1 summarizes some of the recent TMDC-based NZs that have been used for molecular and macromolecular biosensing so far. 
Table 1. TMDC NZs for biosensing applications.

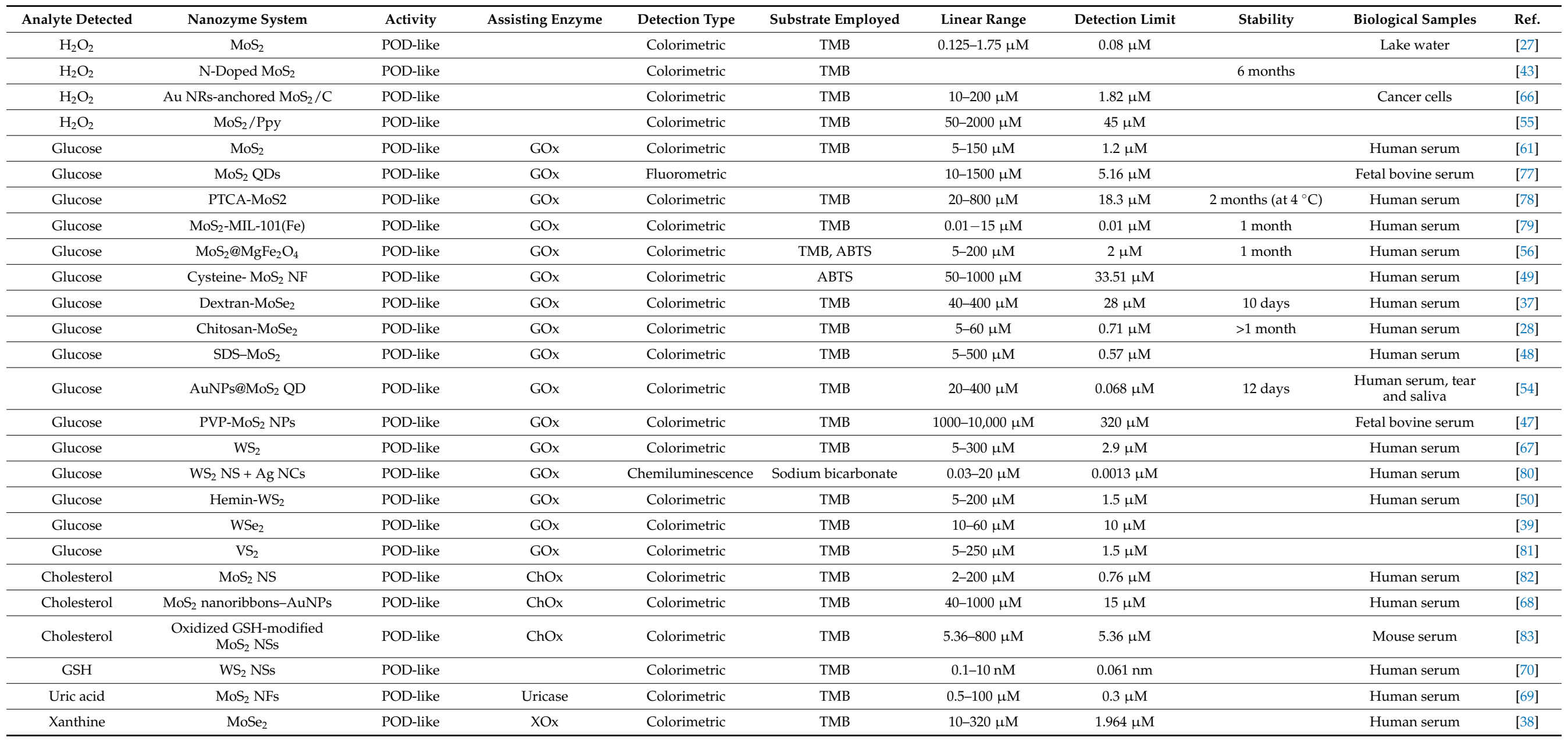


Table 1. Cont.

\begin{tabular}{|c|c|c|c|c|c|c|c|c|c|c|}
\hline Analyte Detected & Nanozyme System & Activity & Assisting Enzyme & Detection Type & Substrate Employed & Linear Range & Detection Limit & Stability & Biological Samples & Ref. \\
\hline Cysteine & $\begin{array}{c}\mathrm{MoS}_{2} \mathrm{QDs}-\mathrm{Ag} \mathrm{NPs} \\
\text { (stimulated by Hg (II) ion) }\end{array}$ & OD-like & & Colorimetric & TMB & $1-100 \mu \mathrm{M}$ & $0.82 \mu \mathrm{M}$ & 1 month & Human serum & [71] \\
\hline CEA & Aptamer/MoS 2 NSs & POD-like & & Colorimetric & TMB & $50-1000 \mathrm{ng} / \mathrm{mL}$ & $50 \mathrm{ng} / \mathrm{mL}$ & & Human serum & [74] \\
\hline Lipase & $\mathrm{MoS}_{2} \mathrm{NPs}$ & POD-like & & Colorimetric & TMB & $5-200 \mathrm{nM}$ & $4.8 \mathrm{nM}$ & & & [72] \\
\hline Mucin 1 & Aptamer-MoS $2 / \mathrm{PtCu}$ & OD-like & NA & Colorimetric & TMB & NA & 300 cells of MCF-7 & & $\begin{array}{c}\text { MCF-7, A549, } \\
\text { HEK293, and HepG2 }\end{array}$ & [58] \\
\hline
\end{tabular}




\subsection{Therapeutics}

\subsubsection{Antibacterial Activity}

The annual increase in the cases of bacterial infections is one of the most challenging aspects of the global public health and safety [84]. In particular, an alarming rise in bacterial drug resistance-as a result of uncontrolled use of antibiotics - has heightened concerns in this context [85]. Significant efforts are being made to overcome this challenge through the development of novel antibacterial agents with greater efficacy and specificity than conventional antibiotics. Recently, a new type of antibacterial therapy with broadband antimicrobial capability, known as nanozyme-mediated antibacterial therapy (NABT), has been introduced. It entails the use of NZs, including TMDC-based, with POD-/OD-like enzymatic activities to regenerate ROS, which then exerts antibacterial effects via oxidation of the bacterial membrane's polysaccharides, proteins, and lipids [52].

The antibacterial activity of TMDC NZs, along with their relatively biocompatible nature, may be advantageous during the wound healing process. Bacterial infections have already been shown to delay healing by increasing inflammatory responses at the wound site [86]. As a result, using appropriate antibacterial agents could help to restore and balance the accurate healing microenvironment and avoid any delays. $\mathrm{MoSe}_{2}$ nanosheets/carboxyl-modified silk fibroin based wound dressing exerted considerable antibacterial effects on Escherichia coli and Bacillus subtilis due to their POD-like activity. The studies were conducted both in vitro and in vivo in E. coli-infected full-skin defect mice model in the presence of low amounts of $\mathrm{H}_{2} \mathrm{O}_{2}$ [87]. Another study used lysozyme, an enzyme capable of hydrolyzing bacterial cell wall peptidoglycan, as an exfoliating agent to generate $\mathrm{MoS}_{2}$ nanosheets. These nanomaterials demonstrated enhanced antibacterial activity against ampicillin-resistant $E$. coli and $B$. subtilis, which was attributed synergistically to the antibacterial activity of lysozyme and the POD-like activity of $\mathrm{MoS}_{2}$ nanosheets [88].

Another intriguing study was conducted by Niu and his colleagues, who used a combination of citraconic anhydride-modified polyethyleneimine (PEI)-MoS $\mathrm{S}_{2}$ nanosheets and a photoacid generator molecule, 2-nitrobenzaldehyde (2-NBA). When 2-NBA was exposed to $365 \mathrm{~nm}$ light, the $\mathrm{pH}$ of the solution decreased, which activated the POD-like activity of the NZs to produce ROS and impart antibacterial effects. Furthermore, the irradiation time changed the charge of the nanomaterial from negative to positive, thanks to the photoreactive characteristics of citraconic anhydride, allowing Gram selectivity for the developed antimicrobial system [89].

Multimodal therapy is usually considered to be more efficient and effective at imparting antibacterial effects. NZs were combined with photothermal and chemotherapy in a study by encapsulating $\mathrm{WS}_{2}$ quantum dots $\left(\mathrm{WS}_{2} \mathrm{QDs}\right)$ and vancomycin in a thermalsensitive liposome. The use of $\mathrm{WS}_{2}$ QDs benefited in two ways: (i) their POD-like activity allowed the generation of ROS and (ii) their photothermal property resulted in heat generation (via $808 \mathrm{~nm}$ NIR laser irradiation), causing liposomal rupturing at the targeted site, resulting in a reduction in drug doses required. This anti-biofilm agent demonstrated excellent anti-biofilm activity, eradicating both E. coli and Mu50 (vancomycin-intermediate Staphylococcus aureus strain) both in vitro and in vivo [60]. Owing to POD-like activity and photothermal properties, PEG-functionalized $\mathrm{MoS}_{2}$ nanoflowers imparted an efficient antimicrobial effect and improved wound healing rate in ampicillin-resistant $E$. coli-infected full-skin defect mice models [90]. Another study used mesoporous ruthenium nanoparticle that was loaded and capped with ascorbic acid prodrug and hyaluronic acid, respectively. Ciprofloxacin-coated $\mathrm{MoS}_{2}$ nanosheets were further bound to the outer surface of the nanocomposite. Post-administration, hyaluronidase enzyme (produced by bacteria) would reduce the hyaluronic acid capping degradation and release of ascorbic acid and $\mathrm{MoS}_{2}$ at the infected wound site. Ascorbic acid/MoS 2 -mediated reactive radical generation, and ruthenium nanoparticles-mediated photothermal therapy, could synergistically eliminate multidrug-resistant bacterial strains in vitro. Furthermore, this therapeutic agent demonstrated promising efficacy in S. aureus-infected mice models (tested for biofilm dispersion inhibition) and S. aureus and Pseudomonas aeruginosa infected mice models (tested for wound 
healing). On the other hand, Ciprofloxacin loading did not affect the antibacterial potency of these nanocomposites [91].

\subsubsection{Cancer Therapy}

Cancer is one of the leading causes of death due to its late diagnosis and insufficient effects of currently available treatments (e.g., chemotherapy, radiation therapy, and surgical treatment) [92]. NZs, including those based on TMDC, have recently gained prominence in cancer treatment. NZ-mediated cancer therapy, like antibacterial systems, uses POD-/ODlike activities to generate ROS and cause cancer cells to die [93].

NZ-mediated cancer therapy is often limited by the lower availability of intra-tumoral $\mathrm{H}_{2} \mathrm{O}_{2}$. To address this challenge, recently, $\mathrm{MoSe}_{2} / \mathrm{CoSe}_{2} @ P E G$ nanosheets were synthesized. Using dissolved $\mathrm{O}_{2}$ and photoexcited electrons, this system was able to produce $\mathrm{H}_{2} \mathrm{O}_{2}$ via a sequential single-electron transfer mechanism. Furthermore, this NZ system showed potent dual POD- and CAT-like activities, which ensured efficient generation of - $\mathrm{OH}$ and $\mathrm{O}_{2}$, respectively. ${ }^{\bullet} \mathrm{OH}$ caused mitochondrial damage, whereas $\mathrm{O}_{2}$ alleviated hypoxia and served as a source of $\mathrm{H}_{2} \mathrm{O}_{2}$. The anticancer effects were amplified by the nanomaterial's excellent photothermal characteristics, as well as redox disruptions (through intracellular GSH reduction). Besides, biodegradability and urinal/fecal elimination (within two weeks post-administration) are other notable features of this therapeutic system [94].

In another study, a glucose-responsive, $\mathrm{H}_{2} \mathrm{O}_{2}$ self-supplying nano-catalytic reactor was developed by self-assembly of GOx, tirapazamine (TPZ) and chitosan on the surface of $\mathrm{MoS}_{2}$ nanosheets. The catalytic mechanisms involved in the cascade are as follows: (i) catalysis of intra-tumoral glucose by $\mathrm{GOx}$ (in the presence of $\mathrm{O}_{2}$ ) to produce $\mathrm{H}_{2} \mathrm{O}_{2}$ and lower the $\mathrm{pH}$; (ii) utilization of $\mathrm{H}_{2} \mathrm{O}_{2}$ by POD-like activity of $\mathrm{MoS}_{2}$ nanosheets to produce ROS-to damage the cancer cells. Meanwhile, depletion of $\mathrm{O}_{2}$ would activate TPZ, whereas $\mathrm{MoS}_{2}$ could utilize GSH to disturb cellular redox balance, further amplifying the anticancer effects. This therapeutic agent demonstrated potent anticancer effects on A549 cells in vitro and A549 tumor-bearing mice models in vivo. In contrast, even at concentrations as high as $100 \mathrm{~g} / \mathrm{mL}$, no cytotoxicity was observed in normal human umbilical vein endothelial cells (HUVEC). Furthermore, under in vivo conditions, these nanomaterials did not accumulate in normal organs, but instead degraded and were cleared out of the body, indicating minimal toxicity to normal tissues [95].

Another significant challenge in the field of nanomedicine is the development of advanced theranostic platforms with both therapeutic and diagnostic capabilities. In this regard, 3D porous $\mathrm{MoS}_{2}$ nanoflowers were synthesized, then loaded with doxorubicin and coated with PEG-PEI (conjugated with LIM Kinase 2 protein (LMP) nucleolar translocation signal peptide). LMP peptide improved the nanomaterials' nuclear targetability in cancer cells. Thus, these materials were able to specifically target the cancer cells and could exert potent anticancer effects both in vitro (4T1 cells) and in vivo (4T1 tumor bearing mice model) through $\mathrm{pH}$-responsive/NIR-enhanced doxorubicin delivery into the tumor cells, NIR-induced photothermal effects along with ROS generation due to POD-like activity of $\mathrm{MoS}_{2}$ nanoflowers. Furthermore, the excellent photoacoustic properties of these materials allowed for real-time tracking post-intravenous in the 4T1 tumor bearing mice models [96]. A smart hybrid NZ based on $\mathrm{MoS}_{2}$-coated bipyramidal gold nanostructure was developed for anticancer therapy and two-photon bioimaging. This hybrid nanomaterial produced considerable ROS due to the POD-like activity of $\mathrm{MoS}_{2}$, which was augmented further by irradiation with $808 \mathrm{~nm}$ NIR laser due to localized plasmonic effects. Such synergistic ROS generation exerted significant anticancer effects in HeLa cells, as confirmed by two-photon luminescence imaging [97].

\subsubsection{Anti-Inflammatory Effect}

Apart from the applications listed above, TMDC NZs, particularly those with CAT /SODlike activity, have also been used as antioxidant materials to provide cytoprotective effects and treat inflammatory diseases/conditions such as osteoarthritis and neurodegenera- 
tion [98-100]. For example, $\mathrm{MoS}_{2}$ nanosheets with CAT/SOD-like activity were synthesized those were able to quench and reduce the levels of free radicals like nitric oxide $\left({ }^{\bullet} \mathrm{NO}\right),{ }^{\bullet} \mathrm{OH}$, and nitrogen-centered free radicals ( $\left.{ }^{\bullet} \mathrm{DPPH}\right)$. Furthermore, treating $\mathrm{H}_{2} \mathrm{O}_{2}$-exposed $\mathrm{A} 549$ cells with these nanomaterials dramatically reduced oxidative stress [99]. Fullerene-like $\mathrm{MoS}_{2}\left(\mathrm{~F}-\mathrm{MoS}_{2}\right)$ is another interesting TMDC-NZs with CAT-/SOD-like activities under physiological settings that appropriate it for using for the non-surgical treatment of osteoarthritis. F- $\mathrm{MoS}_{2}$ was able to catalyze ${ }^{\bullet} \mathrm{O}_{2}{ }^{-}$into $\mathrm{H}_{2} \mathrm{O}_{2}$ and then produce water and $\mathrm{O}_{2}$. Interestingly $\mathrm{F}-\mathrm{MoS}_{2}$ was used to protect HUVEC cells from oxidative stress induced by $\mathrm{H}_{2} \mathrm{O}_{2}$. Besides, $\mathrm{F}-\mathrm{MoS}_{2}$, when coupled with hyaluronic acid (HA), could reduce the excess of ROS and prevent the depolymerization of HA in artificial synovial fluid [100]. TMDC NZ with CAT-/SOD-like activity was used to mitigate the pathology of Alzheimer's disease by targeting neuronal mitochondria with (3-carboxypropyl)triphenyl-phosphonium bromide-conjugated 1,2-distearoyl-sn-glycero-3-phosphoethanolamine- $N$-[amino(PEG)2000]-functionalized $\mathrm{MoS}_{2}$ QDs. When tested in vitro in murine-derived microglia BV2 cells, this nano-formulation dramatically decreased oxidative stress, downregulated proinflammatory cytokines, and elevated anti-inflammatory cytokines. Furthermore, in vitro (in BV2 cells) and in vivo (in an Alzheimer's disease mouse model) tests revealed that these nanomaterials were able to reduce amyloid-beta $(\mathrm{A} \beta)$ aggregation-mediated neurotoxicity and eliminate $A \beta$ aggregates. These were attributed to switching microglial polarization from pro-inflammatory M1 to anti-inflammatory M2, presenting a novel pathway to mitigate Alzheimer's disease pathology [101].

Table 2 listed some of the other studied which were done on the therapeutic application of TMDC NZs. 
Table 2. TMDC NZs for therapeutic applications.

\begin{tabular}{|c|c|c|c|c|c|c|c|c|c|c|}
\hline \multirow{2}{*}{ Applications } & \multirow{2}{*}{ TMDCs Material } & \multirow{2}{*}{ Activity Mimics } & \multirow{2}{*}{$\begin{array}{c}\text { Targeting } \\
\text { Molecule (if Any) }\end{array}$} & \multirow{2}{*}{$\begin{array}{l}\text { Therapeutic } \\
\text { Mechanism }\end{array}$} & \multirow{2}{*}{$\begin{array}{l}\text { Therapeutic } \\
\text { Mediators }\end{array}$} & \multirow{2}{*}{$\begin{array}{l}\text { Light Characteristics } \\
\text { (if Involved) }\end{array}$} & \multicolumn{2}{|c|}{ Activity Assessed Against } & \multirow{2}{*}{$\begin{array}{l}\text { In Vivo } \\
\text { Evaluation }\end{array}$} & \multirow{2}{*}{ Ref. } \\
\hline & & & & & & & Microbial Cells & Mammalian Cells & & \\
\hline \multirow{9}{*}{$\begin{array}{l}\text { Disinfection and } \\
\text { wound healing }\end{array}$} & $\mathrm{MoS}_{2} / \mathrm{rGO}$ & $\begin{array}{l}\text { POD-like, OD-like, } \\
\text { CAT-like }\end{array}$ & & ROS-mediated & $\mathrm{H}_{2} \mathrm{O}_{2}$ & $\begin{array}{c}\text { Xenon lamp } \\
\left(100 \mathrm{~mW} / \mathrm{cm}^{2}\right)\end{array}$ & $\begin{array}{l}\text { Chloramphenicol- } \\
\text { resistant E. coli } \\
\text { and S. aureus }\end{array}$ & & $\begin{array}{l}\text { S. aureus-infected } \\
\text { full-skin defect } \\
\text { mice models }\end{array}$ & [52] \\
\hline & $\mathrm{Fe}_{3} \mathrm{O}_{4} @ \mathrm{MoS}_{2}-\mathrm{Ag}$ & POD-like & & $\begin{array}{l}\mathrm{Ag}+\text { ion-mediated } \\
\text { toxicity, ROS-mediated, } \\
\text { PTT }\end{array}$ & $\mathrm{H}_{2} \mathrm{O}_{2}, \mathrm{Ag}^{+}$ions & $\begin{array}{l}\text { NIR }(808 \mathrm{~nm}, \\
\left.1 \mathrm{~W} / \mathrm{cm}^{2}\right)\end{array}$ & E. coli & & & [102] \\
\hline & $\begin{array}{c}\text { citraconic } \\
\text { anhydride } \\
\text { modified } \\
\text { PEI-MoS } \\
\text { PEI }\end{array}$ & POD-like & & $\begin{array}{l}\text { Disruption of surface } \\
\text { charge, ROS-mediated }\end{array}$ & $\begin{array}{c}\mathrm{H}_{2} \mathrm{O}_{2} \\
\text { 2-nitrobenzaldehyde }\end{array}$ & UV light (365 nm) & $\begin{array}{l}\text { E. coli and } \\
\text { S. aureus }\end{array}$ & & $\begin{array}{l}\text { E. coli and } \\
\text { S. aureus-infected } \\
\text { full-skin defect } \\
\text { mice models }\end{array}$ & [89] \\
\hline & $\begin{array}{c}\mathrm{WS}_{2} \\
\text { QDs-Van@lipo }\end{array}$ & POD-like, OD-like & & $\begin{array}{l}\text { ROS-mediated, PTT, } \\
\text { Chemotherapy }\end{array}$ & $\mathrm{H}_{2} \mathrm{O}_{2}$, vancomycine & $\begin{array}{l}\mathrm{NIR}(808 \mathrm{~nm}, \\
\left.1 \mathrm{~W} / \mathrm{cm}^{2}\right)\end{array}$ & $\begin{array}{l}\text { E. coli and Mu50 } \\
\text { (vancomycin- } \\
\text { intermediate } S \text {. } \\
\text { aureus strain) }\end{array}$ & & $\begin{array}{l}\text { Mice models with } \\
\text { Mu50-infected } \\
\text { abscess }\end{array}$ & [60] \\
\hline & $\begin{array}{c}\text { Cu NW-supported } \\
\mathrm{MoS}_{2} \mathrm{NS}\end{array}$ & POD-like & & ROS-mediated, PTT & $\mathrm{H}_{2} \mathrm{O}_{2}$ & $\begin{array}{l}\text { NIR }(808 \mathrm{~nm}, \\
\left.1 \mathrm{~W} / \mathrm{cm}^{2}\right)\end{array}$ & $\begin{array}{l}\text { E. coli and } \\
\text { S. aureus }\end{array}$ & & $\begin{array}{l}\text { MRSA-infected } \\
\text { full-skin defect } \\
\text { mice models }\end{array}$ & [51] \\
\hline & $\begin{array}{l}\text { N-doped } \mathrm{MoS}_{2} \\
\mathrm{~N} \text {-doped } \mathrm{WS}_{2}\end{array}$ & POD-like & & ROS-mediated & $\mathrm{H}_{2} \mathrm{O}_{2}$ & & $\begin{array}{l}\text { Ampicillin } \\
\text { resistant E. coli } \\
\text { and B. subtilis }\end{array}$ & & $\begin{array}{l}\text { Ampicillin } \\
\text { resistant } E \text {. } \\
\text { coli-infected } \\
\text { full-skin defect } \\
\text { mice models }\end{array}$ & [42] \\
\hline & $\begin{array}{c}\text { Lysozyme } \\
\text { exfoliated } \mathrm{MoS}_{2} \\
\text { NSs }\end{array}$ & POD-like & & ROS-mediated & $\mathrm{H}_{2} \mathrm{O}_{2}$ & & $\begin{array}{l}\text { Ampicillin- } \\
\text { resistant } E \text {. coli } \\
\text { and B. subtilis }\end{array}$ & & & [88] \\
\hline & PEG-MoS 2 NFs & POD-like & & $\begin{array}{l}\text { ROS-mediated, } \\
\text { Photothermal therapy } \\
\text { (PTT) }\end{array}$ & $\mathrm{H}_{2} \mathrm{O}_{2}$ & $\begin{array}{l}\mathrm{NIR}(808 \mathrm{~nm}, \\
\left.1 \mathrm{~W} / \mathrm{cm}^{2}\right)\end{array}$ & $\begin{array}{l}\text { Ampicillin- } \\
\text { resistant E. coli } \\
\text { and B. subtilis }\end{array}$ & & $\begin{array}{l}\text { Ampicillin } \\
\text { resistant } E \text {. } \\
\text { coli-infected } \\
\text { full-skin defect } \\
\text { mice models }\end{array}$ & [90] \\
\hline & $\mathrm{CMSF} \mathrm{MoSe}_{2} \mathrm{NSs}$ & POD-like & & ROS-mediated & $\mathrm{H}_{2} \mathrm{O}_{2}$ & & $\begin{array}{l}\text { E. coli and } \\
\text { B. subtilis }\end{array}$ & & $\begin{array}{l}\text { E. coli-infected } \\
\text { full-skin defect } \\
\text { mice models }\end{array}$ & [87] \\
\hline
\end{tabular}


Table 2. Cont.

\begin{tabular}{|c|c|c|c|c|c|c|c|c|c|c|}
\hline \multirow{2}{*}{ Applications } & \multirow{2}{*}{ TMDCs Material } & \multirow{2}{*}{ Activity Mimics } & \multirow{2}{*}{$\begin{array}{c}\text { Targeting } \\
\text { Molecule (if Any) }\end{array}$} & \multirow{2}{*}{$\begin{array}{l}\text { Therapeutic } \\
\text { Mechanism }\end{array}$} & \multirow{2}{*}{$\begin{array}{l}\text { Therapeutic } \\
\text { Mediators }\end{array}$} & \multirow{2}{*}{$\begin{array}{l}\text { Light Characteristics } \\
\text { (if Involved) }\end{array}$} & \multicolumn{2}{|c|}{ Activity Assessed Against } & \multirow{2}{*}{$\begin{array}{l}\text { In Vivo } \\
\text { Evaluation }\end{array}$} & \multirow{2}{*}{ Ref. } \\
\hline & & & & & & & Microbial Cells & Mammalian Cells & & \\
\hline \multirow{4}{*}{$\begin{array}{l}\text { Anticancer } \\
\text { therapy }\end{array}$} & $\begin{array}{c}\text { Glucose } \\
\text { responsive, } \\
\text { TMZ-loaded } \\
\text { chitosan-MoS } \\
\end{array}$ & POD-like & & $\begin{array}{l}\text { ROS-mediated, GSH } \\
\text { depletion, hypoxia } \\
\text { induced TPZ activation }\end{array}$ & $\mathrm{H}_{2} \mathrm{O}_{2}$ and TPZ & & & A549 cells & $\begin{array}{c}\text { A549 } \\
\text { tumor-bearing } \\
\text { mice models }\end{array}$ & [95] \\
\hline & AuNBPs@MoS 2 & POD-like & & ROS-mediated, PTT & $\mathrm{H}_{2} \mathrm{O}_{2}$ & $\begin{array}{l}\text { NIR laser }(808 \mathrm{~nm}, \\
\left.2.0 \mathrm{~W} / \mathrm{cm}^{2}\right)\end{array}$ & & HeLa cells & & [97] \\
\hline & $\begin{array}{c}\text { LNP-PEG-PEI } \\
\text { coated, Dox } \\
\text { loaded } \mathrm{MoS}_{2} \mathrm{NFs}\end{array}$ & POD-like & $\begin{array}{l}\text { LNP nucleolar } \\
\text { translocation } \\
\text { signal peptide }\end{array}$ & $\begin{array}{l}\text { ROS-mediated, CT, } \\
\text { PTT, PDT }\end{array}$ & Dox & $\begin{array}{l}\text { NIR laser }(808 \mathrm{~nm}, \\
\left.\quad 3.0 \mathrm{~W} / \mathrm{cm}^{2}\right)\end{array}$ & & $4 \mathrm{~T} 1$ cells & $\begin{array}{l}4 \mathrm{~T} 1 \text { tumor-bearing } \\
\text { mice models }\end{array}$ & [96] \\
\hline & $\mathrm{MoSe}_{2} / \mathrm{CoSe}_{2} @ \mathrm{PEG}$ & $\begin{array}{l}\text { POD-like, } \\
\text { CAT-like }\end{array}$ & & $\begin{array}{c}\text { ROS-mediated, GSH } \\
\text { depletion, PTT }\end{array}$ & $\mathrm{H}_{2} \mathrm{O}_{2}$ & $\begin{array}{l}\text { NIR laser }(808 \mathrm{~nm}, \\
\left.1.0 \mathrm{~W} / \mathrm{cm}^{2}\right)\end{array}$ & & HepG2 cells & $\begin{array}{l}\text { Tumor-bearing } \\
\text { mice models }\end{array}$ & [94] \\
\hline Cytoprotection & $\mathrm{MoS}_{2} \mathrm{NS}$ & $\begin{array}{l}\text { CAT-like, } \\
\text { SOD-like, } \\
\text { POD-like }\end{array}$ & & $\begin{array}{l}\text { Scavenging oxidative } \\
\text { stress species }\end{array}$ & & & $\begin{array}{l}\text { E. coli and } \\
\text { S. aureus }\end{array}$ & A549 cells & & [99] \\
\hline Neurodegeneration & TPP-MoS 2 QDs & $\begin{array}{l}\text { CAT-like, } \\
\text { SOD-like }\end{array}$ & $\begin{array}{c}\text { TPP } \\
\text { (mitochondrial } \\
\text { targeting) }\end{array}$ & $\begin{array}{l}\text { Scavenging oxidative } \\
\text { stress species }\end{array}$ & & & & BV-2 cells & $\begin{array}{c}\text { Amyloid } \\
\text { precursor } \\
\text { protein/presenilin } \\
\text { 1(APP/PS1) } \\
\text { double transgenic } \\
\text { mice } \\
\end{array}$ & [101] \\
\hline
\end{tabular}




\section{Conclusions and Outlook}

As of today, NZs have presented themselves as a superior alternative to natural enzymes in various sectors, including industrial, environmental, healthcare, and diagnostics. This review highlights the current advancements made with TMDC NZs. As described in the text, nano-architectural features, high surface area, semiconducting properties with tunable band gaps, chemical/physical modifications, and environmental factors represent key factors regulating the intrinsic enzymatic properties of TMDCs and ensured their biomedical applicability. To date, TMDC NZs with POD-/OD-/CAT-/SOD-mimicking activities have been reported for applications such as biosensing, antibacterial, anticancer, and anti-inflammatory activities. However, to truly move forward, on one hand, we need to work upon certain aspects, including their rational design, microenvironment descriptions, expansion from single to multi-activity mimics, incorporating multi-functionality, and addressing biological effects [103], while on the other hand, new TMDC NZs should be investigated. Controlled synthesis of TMDC NZs is essential to achieve a desirable colloidal stability, uniform size, high yield and enzymatic performance [104]. Furthermore, a limited understanding of the optimal structural features and associated catalytic mechanisms, it becomes quite tricky to predict the selectivity and activity of TMDC NZs. In this regard, appropriate theoretical and experimental models should be established to better understand their structure-function relationship, thereby rationalizing the design of NZs for a specific biomedical application [13,105]. Besides, speculating their biocompatibility, biodistribution, biodegradation, metabolism, short-term and long-term toxicity, and immunogenicity is highly desirable for biological applications. In particular, the functionalization of TMDCs is an attractive approach to modulate these aspects. Moreover, integrating stimuli-responsive features and multi-functional capabilities within these materials could impart better controllability over their performance and reduce undesirable effects (particularly when targeting in vivo therapeutic applications).

In conclusion, despite significant progress achieved in the TMDC NZs field, several aspects still need to be appropriately defined, and the development of novel TMDC NZs could be helpful in facing these issues. Nowadays, the synthesis of uniform structures, scalability, and the reduction of the synthesis costs are the main ongoing challenges. Additionally, it is essential to underline that TMDC NZs are still in the early stage of their use compared to other nanomaterials, such as spherical nanomaterials. Therefore, further in vitro and in vivo pre-clinical studies are needed to thoroughly investigate their biocompatibility and potential side effects. In this context, approaches based on bioinformatics tools coupled with machine learning and artificial intelligence could predict novel TMDC NZs with high enzymatic performance.

Author Contributions: D.P.: Writing-Original draft, Writing-Reviewing and Editing; T.A.: Conceptualization, Data collection and compilation, Writing-Original draft, Writing-Reviewing and Editing, Figure preparation; A.Z. (Atefeh Zarepour): Writing-Original draft; S.H.: Writing-Original draft; N.C.: Writing-Original draft; C.N.: Data collection and compilation; M.G.: Writing-Original draft; A.Z. (Ali Zarrabi): Writing-Reviewing and Editing; M.C.: Writing-Reviewing and Editing; B.B.: Writing-Reviewing and editing; T.K.M.: Writing-Reviewing and Editing. All authors have read and agreed to the published version of the manuscript.

Funding: This work is supported by the National Science Centre Poland (NCN) within PRELUDIUM19 Project No. 2020/37/N/ST5/03272 to NC. The authors are grateful for the support to this work also provided by the National Science Centre Poland (NCN) within OPUS 19 Project No. 2020/37/B/ST8/02167 to MC.

Institutional Review Board Statement: Not applicable.

Informed Consent Statement: Not applicable.

Data Availability Statement: All data contained within the article. 
Acknowledgments: T.A. acknowledges the INSPIRE scheme, Department of Science and Technology, Government of India, for providing the fellowship (DST/INSPIRE/03/2015/003251). Images were created with Biorender.com, accessed on 22 November 2021.

Conflicts of Interest: The authors declare that they have no known competing financial interests or personal relationships that could have appeared to influence the work reported in this paper.

\section{References}

1. Setua, S.; Jaggi, M.; Yallapu, M.M.; Chauhan, S.C.; Danilushkina, A.; Lee, H.; Choi, I.S.; Fakhrullin, R.; Esposti, L.D.; Tampieri, A.; et al. Targeted and theranostic applications for nanotechnologies in medicine. In Nanotechnologies in Preventive and Regenerative Medicine; Uskoković, V., Uskoković, D.P., Eds.; Elsevier: Amsterdam, The Netherlands, 2018 ; pp. 399-511. ISBN 978-0-323-48063-5.

2. Wang, H.; Wan, K.; Shi, X. Recent Advances in Nanozyme Research. Adv. Mater. 2019, 31, 1805368. [CrossRef] [PubMed]

3. Gutierrez, R.M.P.; Mendez, J.V.M.; Vazquez, I.A. A novel approach to the oral delivery of bionanostructures for systemic disease. In Nanostructures for Oral Medicine; Andronescu, E., Grumezescu, A.M., Eds.; Elsevier: Amsterdam, The Netherlands, 2017; pp. 27-59. ISBN 978-0-323-47720-8.

4. Rinoldi, C.; Zargarian, S.S.; Nakielski, P.; Li, X.; Liguori, A.; Petronella, F.; Presutti, D.; Wang, Q.; Costantini, M.; De Sio, L.; et al. Nanotechnology-Assisted RNA Delivery: From Nucleic Acid Therapeutics to COVID-19 Vaccines. Small Methods 2021, 5, 2100402. [CrossRef]

5. Raja, I.S.; Kang, M.S.; Kim, K.S.; Jung, Y.J.; Han, D.-W. Two-Dimensional Theranostic Nanomaterials in Cancer Treatment: State of the Art and Perspectives. Cancers 2020, 12, 1657. [CrossRef]

6. Lim, E.-K.; Kim, T.; Paik, S.; Haam, S.; Huh, Y.-M.; Lee, K. Nanomaterials for Theranostics: Recent Advances and Future Challenges. Chem. Rev. 2015, 115, 327-394. [CrossRef]

7. Alizadeh, N.; Salimi, A. Multienzymes activity of metals and metal oxide nanomaterials: Applications from biotechnology to medicine and environmental engineering. J. Nanobiotechnol. 2021, 19, 26. [CrossRef] [PubMed]

8. Huang, Y.; Ren, J.; Qu, X. Nanozymes: Classification, Catalytic Mechanisms, Activity Regulation, and Applications. Chem. Rev. 2019, 119, 4357-4412. [CrossRef]

9. Shin, H.Y.; Park, T.J.; Kim, M.I. Recent Research Trends and Future Prospects in Nanozymes. J. Nanomater. 2015, 2015, 7. [CrossRef]

10. Li, Y.; Liu, J. Nanozyme's catching up: Activity, specificity, reaction conditions and reaction types. Mater. Horizons 2021, 8, 336-350. [CrossRef]

11. Wei, H.; Wang, E. Nanomaterials with enzyme-like characteristics (nanozymes): Next-generation artificial enzymes. Chem. Soc. Rev. 2013, 42, 6060. [CrossRef]

12. Jiang, D.; Ni, D.; Rosenkrans, Z.T.; Huang, P.; Yan, X.; Cai, W. Nanozyme: New horizons for responsive biomedical applications. Chem. Soc. Rev. 2019, 48, 3683-3704. [CrossRef]

13. Cai, S.; Yang, R. Two-Dimensional Nanomaterials with Enzyme-Like Properties for Biomedical Applications. Front. Chem. 2020, 8 , 1109. [CrossRef]

14. Zhang, H. Ultrathin Two-Dimensional Nanomaterials. ACS Nano 2015, 9, 9451-9469. [CrossRef]

15. Meng, S.; Zhang, Y.; Wang, H.; Wang, L.; Kong, T.; Zhang, H.; Meng, S. Recent advances on TMDCs for medical diagnosis. Biomaterials 2021, 269, 120471. [CrossRef] [PubMed]

16. Bolotsky, A.; Butler, D.; Dong, C.; Gerace, K.; Glavin, N.R.; Muratore, C.; Robinson, J.A.; Ebrahimi, A. Two-Dimensional Materials in Biosensing and Healthcare: From In Vitro Diagnostics to Optogenetics and Beyond. ACS Nano 2019, 13, 9781-9810. [CrossRef] [PubMed]

17. Wang, H.; Yuan, H.; Sae Hong, S.; Li, Y.; Cui, Y. Physical and chemical tuning of two-dimensional transition metal dichalcogenides. Chem. Soc. Rev. 2015, 44, 2664-2680. [CrossRef]

18. Manzeli, S.; Ovchinnikov, D.; Pasquier, D.; Yazyev, O.V.; Kis, A. 2D transition metal dichalcogenides. Nat. Rev. Mater. 2017, 2, 17033. [CrossRef]

19. Parvez, K. Two-Dimensional Nanomaterials: Crystal Structure and Synthesis. In Biomedical Applications of Graphene and $2 \mathrm{D}$ Nanomaterials; Nurunnabi, M., McCarthy, J.R., Eds.; Elsevier: Amsterdam, The Netherlands, 2019; pp. 1-25. ISBN 978-0-12-815889-0.

20. Anju, S.; Mohanan, P.V. Biomedical applications of transition metal dichalcogenides (TMDCs). Synth. Met. 2021, $271,116610$. [CrossRef]

21. Cheng, L.; Liu, J.; Gu, X.; Gong, H.; Shi, X.; Liu, T.; Wang, C.; Wang, X.; Liu, G.; Xing, H.; et al. PEGylated WS 2 Nanosheets as a Multifunctional Theranostic Agent for in vivo Dual-Modal CT/Photoacoustic Imaging Guided Photothermal Therapy. Adv. Mater. 2014, 26, 1886-1893. [CrossRef]

22. Zu, Y.; Yao, H.; Wang, Y.; Yan, L.; Gu, Z.; Chen, C.; Gao, L.; Yin, W. The age of bioinspired molybdenum-involved nanozymes: Synthesis, catalytic mechanisms, and biomedical applications. VIEW 2021, 2, 20200188. [CrossRef]

23. Wang, P.; Sun, H.; Ji, Y.; Li, W.; Wang, X. Three-Dimensional Assembly of Single-Layered MoS2. Adv. Mater. 2014, 26, 964-969. [CrossRef] [PubMed]

24. Fan, R.; Chen, X.; Chen, Z. A Novel Route to Obtain Molybdenum Dichalcogenides by Hydrothermal Reaction. Chem. Lett. 2000, 29, 920-921. [CrossRef] 
25. Zhan, J.H.; Zhang, Z.D.; Qian, X.F.; Wang, C.; Xie, Y.; Qian, Y.T. Solvothermal Synthesis of Nanocrystalline $\mathrm{MoS}_{2}$ from $\mathrm{MoO}_{3}$ and Elemental Sulfur. J. Solid State Chem. 1998, 141, 270-273. [CrossRef]

26. Shi, W.; Song, S.; Zhang, H. Hydrothermal synthetic strategies of inorganic semiconducting nanostructures. Chem. Soc. Rev. 2013, 42, 5714-5743. [CrossRef] [PubMed]

27. Guo, X.; Wang, Y.; Wu, F.; Ni, Y.; Kokot, S. A colorimetric method of analysis for trace amounts of hydrogen peroxide with the use of the nano-properties of molybdenum disulfide. Analyst 2015, 140, 1119-1126. [CrossRef]

28. Liu, D.; Wang, D.; Jing, X.; Zhao, X.; Xi, D.; Dang, D.; Meng, L. Continuous phase regulation of MoSe 2 from $2 \mathrm{H}$ to $1 \mathrm{~T}$ for the optimization of peroxidase-like catalysis. J. Mater. Chem. B 2020, 8, 6451-6458. [CrossRef] [PubMed]

29. Haddad Irani-nezhad, M.; Khataee, A.; Hassanzadeh, J.; Orooji, Y. A Chemiluminescent Method for the Detection of $\mathrm{H}_{2} \mathrm{O}_{2}$ and Glucose Based on Intrinsic Peroxidase-Like Activity of $\mathrm{WS}_{2}$ Quantum Dots. Molecules 2019, 24, 689. [CrossRef]

30. Gao, Q.; Zhang, Z.; Xu, X.; Song, J.; Li, X.; Wu, Y. Scalable high performance radio frequency electronics based on large domain bilayer $\mathrm{MoS}_{2}$. Nat. Commun. 2018, 9, 4778. [CrossRef] [PubMed]

31. Zhang, Y.; Yao, Y.; Sendeku, M.G.; Yin, L.; Zhan, X.; Wang, F.; Wang, Z.; He, J. Recent Progress in CVD Growth of 2D Transition Metal Dichalcogenides and Related Heterostructures. Adv. Mater. 2019, 31, 1901694. [CrossRef] [PubMed]

32. Gao, Y.; Hong, Y.-L.; Yin, L.-C.; Wu, Z.; Yang, Z.; Chen, M.-L.; Liu, Z.; Ma, T.; Sun, D.-M.; Ni, Z.; et al. Ultrafast Growth of High-Quality Monolayer WSe ${ }_{2}$ on Au. Adv. Mater. 2017, 29, 1700990. [CrossRef]

33. Appel, J.H.; Li, D.O.; Podlevsky, J.D.; Debnath, A.; Green, A.A.; Wang, Q.H.; Chae, J. Low Cytotoxicity and Genotoxicity of Two-Dimensional $\mathrm{MoS}_{2}$ and $\mathrm{WS}_{2}$. ACS Biomater. Sci. Eng. 2016, 2, 361-367. [CrossRef] [PubMed]

34. Chen, X.; Park, Y.J.; Kang, M.; Kang, S.-K.; Koo, J.; Shinde, S.M.; Shin, J.; Jeon, S.; Park, G.; Yan, Y.; et al. CVD-grown monolayer $\mathrm{MoS}_{2}$ in bioabsorbable electronics and biosensors. Nat. Commun. 2018, 9, 1690. [CrossRef]

35. Xie, L.M. Two-dimensional transition metal dichalcogenide alloys: Preparation, characterization and applications. Nanoscale 2015, 7, 18392-18401. [CrossRef]

36. Kang, K.; Chen, S.; Yang, E.-H. Synthesis of transition metal dichalcogenides. In Synthesis, Modeling, and Characterization of 2D Materials, and Their Heterostructures; Yang, E.-H., Datta, D., Ding, J., Hader, G., Eds.; Elsevier: Amsterdam, The Netherlands, 2020; pp. 247-264. ISBN 978-0-12-818475-2.

37. Jiang, G.; Lin, T.; Qin, Y.; Zhang, X.; Hou, L.; Sun, Y.; Huang, J.; Liu, S.; Zhao, S. Accelerating the peroxidase-like activity of MoSe 2 nanosheets at physiological $\mathrm{pH}$ by dextran modification. Chem. Commun. 2020, 56, 10847-10850. [CrossRef]

38. Wu, X.; Chen, T.; Wang, J.; Yang, G. Few-layered $\mathrm{MoSe}_{2}$ nanosheets as an efficient peroxidase nanozyme for highly sensitive colorimetric detection of $\mathrm{H}_{2} \mathrm{O}_{2}$ and xanthine. J. Mater. Chem. B 2018, 6, 105-111. [CrossRef] [PubMed]

39. Chen, T.M.; Wu, X.J.; Wang, J.X.; Yang, G.W. WSe 2 few layers with enzyme mimic activity for high-sensitive and high-selective visual detection of glucose. Nanoscale 2017, 9, 11806-11813. [CrossRef]

40. Huang, L.; Zhu, Q.; Zhu, J.; Luo, L.; Pu, S.; Zhang, W.; Zhu, W.; Sun, J.; Wang, J. Portable Colorimetric Detection of Mercury(II) Based on a Non-Noble Metal Nanozyme with Tunable Activity. Inorg. Chem. 2019, 58, 1638-1646. [CrossRef]

41. Zeng, Z.; Yin, Z.; Huang, X.; Li, H.; He, Q.; Lu, G.; Boey, F.; Zhang, H. Single-Layer Semiconducting Nanosheets: High-Yield Preparation and Device Fabrication. Angew. Chem. Int. Ed. 2011, 50, 11093-11097. [CrossRef] [PubMed]

42. Wang, T.; Zhang, X.; Mei, L.; Ma, D.; Liao, Y.; Zu, Y.; Xu, P.; Yin, W.; Gu, Z. A two-step gas/liquid strategy for the production of N-doped defect-rich transition metal dichalcogenide nanosheets and their antibacterial applications. Nanoscale 2020, 12, 8415-8424. [CrossRef]

43. Feng, L.; Zhang, L.; Zhang, S.; Chen, X.; Li, P.; Gao, Y.; Xie, S.; Zhang, A.; Wang, H. Plasma-Assisted Controllable Doping of Nitrogen into $\mathrm{MoS}_{2}$ Nanosheets as Efficient Nanozymes with Enhanced Peroxidase-Like Catalysis Activity. ACS Appl. Mater. Interfaces 2020, 12, 17547-17556. [CrossRef] [PubMed]

44. Cadiz, F.; Courtade, E.; Robert, C.; Wang, G.; Shen, Y.; Cai, H.; Taniguchi, T.; Watanabe, K.; Carrere, H.; Lagarde, D.; et al. Excitonic Linewidth Approaching the Homogeneous Limit in $\mathrm{MoS}_{2}$-Based van der Waals Heterostructures. Phys. Rev. X 2017, 7, 021026. [CrossRef]

45. Suh, J.; Park, T.-E.; Lin, D.-Y.; Fu, D.; Park, J.; Jung, H.J.; Chen, Y.; Ko, C.; Jang, C.; Sun, Y.; et al. Doping against the Native Propensity of $\mathrm{MoS}_{2}$ : Degenerate Hole Doping by Cation Substitution. Nano Lett. 2014, 14, 6976-6982. [CrossRef]

46. Zhang, K.; Bersch, B.M.; Joshi, J.; Addou, R.; Cormier, C.R.; Zhang, C.; Xu, K.; Briggs, N.C.; Wang, K.; Subramanian, S.; et al Tuning the Electronic and Photonic Properties of Monolayer $\mathrm{MoS}_{2}$ via In Situ Rhenium Substitutional Doping. Adv. Funct. Mater. 2018, 28, 1706950. [CrossRef]

47. Yu, J.; Ma, X.; Yin, W.; Gu, Z. Synthesis of PVP-functionalized ultra-small $\mathrm{MoS}_{2}$ nanoparticles with intrinsic peroxidase-like activity for $\mathrm{H} 2 \mathrm{O} 2$ and glucose detection. RSC Adv. 2016, 6, 81174-81183. [CrossRef]

48. Zhao, K.; Gu, W.; Zheng, S.; Zhang, C.; Xian, Y. SDS-MoS ${ }_{2}$ nanoparticles as highly-efficient peroxidase mimetics for colorimetric detection of $\mathrm{H}_{2} \mathrm{O}_{2}$ and glucose. Talanta 2015, 141, 47-52. [CrossRef]

49. Yu, J.; Ma, D.; Mei, L.; Gao, Q.; Yin, W.; Zhang, X.; Yan, L.; Gu, Z.; Ma, X.; Zhao, Y. Peroxidase-like activity of MoS 2 nanoflakes with different modifications and their application for $\mathrm{H}_{2} \mathrm{O}_{2}$ and glucose detection. J. Mater. Chem. B 2018, 6, 487-498. [CrossRef] [PubMed]

50. Chen, Q.; Chen, J.; Gao, C.; Zhang, M.; Chen, J.; Qiu, H. Hemin-functionalized $\mathrm{WS}_{2}$ nanosheets as highly active peroxidase mimetics for label-free colorimetric detection of $\mathrm{H}_{2} \mathrm{O}_{2}$ and glucose. Analyst 2015, 140, 2857-2863. [CrossRef] 
51. Cao, F.; Zhang, L.; Wang, H.; You, Y.; Wang, Y.; Gao, N.; Ren, J.; Qu, X. Defect-Rich Adhesive Nanozymes as Efficient Antibiotics for Enhanced Bacterial Inhibition. Angew. Chem. Int. Ed. 2019, 58, 16236-16242. [CrossRef] [PubMed]

52. Wang, L.; Gao, F.; Wang, A.; Chen, X.; Li, H.; Zhang, X.; Zheng, H.; Ji, R.; Li, B.; Yu, X.; et al. Defect-Rich Adhesive Molybdenum Disulfide/rGO Vertical Heterostructures with Enhanced Nanozyme Activity for Smart Bacterial Killing Application. Adv. Mater. 2020, 32, 2005423. [CrossRef]

53. Liu, X.; Huang, L.; Wang, Y.; Sun, J.; Yue, T.; Zhang, W.; Wang, J. One-pot bottom-up fabrication of a 2D/2D heterojuncted nanozyme towards optimized peroxidase-like activity for sulfide ions sensing. Sens. Actuators B Chem. 2020, $306,127565$. [CrossRef]

54. Vinita; Nirala, N.R.; Prakash, R. One step synthesis of AuNPs@MoS 2 -QDs composite as a robust peroxidase- mimetic for instant unaided eye detection of glucose in serum, saliva and tear. Sens. Actuators B Chem. 2018, 263, 109-119. [CrossRef]

55. Lei, J.; Lu, X.; Nie, G.; Jiang, Z.; Wang, C. One-Pot Synthesis of Algae-Like $\mathrm{MoS}_{2}$ /PPy Nanocomposite: A Synergistic Catalyst with Superior Peroxidase-Like Catalytic Activity for $\mathrm{H}_{2} \mathrm{O}_{2}$ Detection. Part. Part Syst. Charact. 2015, 32, 886-892. [CrossRef]

56. Zhang, Y.; Zhou, Z.; Wen, F.; Tan, J.; Peng, T.; Luo, B.; Wang, H.; Yin, S. A flower-like $\mathrm{MoS}_{2}$-decorated $\mathrm{MgFe}_{2} \mathrm{O}_{4}$ nanocomposite: Mimicking peroxidase and colorimetric detection of $\mathrm{H}_{2} \mathrm{O}_{2}$ and glucose. Sens. Actuators B Chem. 2018, 275, 155-162. [CrossRef]

57. Wang, Y.; Qi, K.; Yu, S.; Jia, G.; Cheng, Z.; Zheng, L.; Wu, Q.; Bao, Q.; Wang, Q.; Zhao, J.; et al. Revealing the Intrinsic Peroxidase-Like Catalytic Mechanism of Heterogeneous Single-Atom Co-MoS . Nano-Micro Lett. 2019, 11, 102. [CrossRef]

58. Qi, C.; Cai, S.; Wang, X.; Li, J.; Lian, Z.; Sun, S.; Yang, R.; Wang, C. Enhanced oxidase/peroxidase-like activities of aptamer conjugated $\mathrm{MoS}_{2} / \mathrm{PtCu}$ nanocomposites and their biosensing application. RSC Adv. 2016, 6, 54949-54955. [CrossRef]

59. Dey, S.; Matte, H.S.S.R.; Shirodkar, S.N.; Waghmare, U.V.; Rao, C.N.R. Charge-Transfer Interaction between Few-Layer MoS 2 and Tetrathiafulvalene. Chem. Asian J. 2013, 8, 1780-1784. [CrossRef]

60. Xu, M.; Hu, Y.; Xiao, Y.; Zhang, Y.; Sun, K.; Wu, T.; Lv, N.; Wang, W.; Ding, W.; Li, F.; et al. Near-Infrared-Controlled Nanoplatform Exploiting Photothermal Promotion of Peroxidase-like and OXD-like Activities for Potent Antibacterial and Anti-biofilm Therapies. ACS Appl. Mater. Interfaces 2020, 12, 50260-50274. [CrossRef]

61. Lin, T.; Zhong, L.; Guo, L.; Fu, F.; Chen, G. Seeing diabetes: Visual detection of glucose based on the intrinsic peroxidase-like activity of $\mathrm{MoS}_{2}$ nanosheets. Nanoscale 2014, 6, 11856-11862. [CrossRef]

62. Nandu, N.; Smith, C.W.; Kachwala, M.J.; Yigit, M.V. Regulation of the Peroxidase-Like Activity of nGO, MoS 2 and WS 2 Nanozymes by Using Metal Cations. ChemBioChem 2021, 22, 662-665. [CrossRef]

63. Tang, Y.; Hu, Y.; Yang, Y.; Liu, B.; Wu, Y. A facile colorimetric sensor for ultrasensitive and selective detection of Lead(II) in environmental and biological samples based on intrinsic peroxidase-mimic activity of $\mathrm{WS}_{2}$ nanosheets. Anal. Chim. Acta 2020, 1106, 115-125. [CrossRef]

64. Mohankumar, P.; Ajayan, J.; Mohanraj, T.; Yasodharan, R. Recent developments in biosensors for healthcare and biomedical applications: A review. Measurement 2021, 167, 108293. [CrossRef]

65. Makvandi, P.; Zarepour, A.; Zheng, X.; Agarwal, T.; Ghomi, M.; Sartorius, R.; Zare, E.N.; Zarrabi, A.; Wu, A.; Maiti, T.K.; et al. Non-spherical nanostructures in nanomedicine: From noble metal nanorods to transition metal dichalcogenide nanosheets. Appl. Mater. Today 2021, 24, 101107. [CrossRef]

66. Sun, H.; Gao, Y.; Hu, N.; Zhang, Y.; Guo, C.; Gao, G.; Ma, Z.; Ivan Ivanovich, K.; Qiu, Y. Electronic coupling between molybdenum disulfide and gold nanoparticles to enhance the peroxidase activity for the colorimetric immunoassays of hydrogen peroxide and cancer cells. J. Colloid Interface Sci. 2020, 578, 366-378. [CrossRef] [PubMed]

67. Lin, T.; Zhong, L.; Song, Z.; Guo, L.; Wu, H.; Guo, Q.; Chen, Y.; Fu, F.; Chen, G. Visual detection of blood glucose based on peroxidase-like activity of $\mathrm{WS}_{2}$ nanosheets. Biosens. Bioelectron. 2014, 62, 302-307. [CrossRef] [PubMed]

68. Nirala, N.R.; Pandey, S.; Bansal, A.; Singh, V.K.; Mukherjee, B.; Saxena, P.S.; Srivastava, A. Different shades of cholesterol: Gold nanoparticles supported on $\mathrm{MoS}_{2}$ nanoribbons for enhanced colorimetric sensing of free cholesterol. Biosens. Bioelectron. 2015, 74, 207-213. [CrossRef] [PubMed]

69. Wang, X.; Yao, Q.; Tang, X.; Zhong, H.; Qiu, P.; Wang, X. A highly selective and sensitive colorimetric detection of uric acid in human serum based on $\mathrm{MoS}_{2}$-catalyzed oxidation TMB. Anal. Bioanal. Chem. 2019, 411, 943-952. [CrossRef]

70. Li, L.; Wang, Q.; Chen, Z. Colorimetric detection of glutathione based on its inhibitory effect on the peroxidase-mimicking properties of $\mathrm{WS}_{2}$ nanosheets. Microchim. Acta 2019, 186, 257. [CrossRef]

71. Ojha, R.P.; Mishra, R.; Singh, P.; Nirala, N.R.; Prakash, R. A composite prepared from $\mathrm{MoS}_{2}$ quantum dots and silver nanoparticles and stimulated by mercury(II) is a robust oxidase mimetic for use in visual determination of cysteine. Microchim. Acta 2020, 187, 74. [CrossRef]

72. Nandu, N.; Salih Hizir, M.; Roberston, N.M.; Ozturk, B.; Yigit, M.V. Masking the Peroxidase-Like Activity of the Molybdenum Disulfide Nanozyme Enables Label-Free Lipase Detection. ChemBioChem 2019, 20, 1861-1867. [CrossRef]

73. Bunka, D.H.J.; Stockley, P.G. Aptamers come of age-At last. Nat. Rev. Microbiol. 2006, 4, 588-596. [CrossRef] [PubMed]

74. Zhao, L.; Wang, J.; Su, D.; Zhang, Y.; Lu, H.; Yan, X.; Bai, J.; Gao, Y.; Lu, G. The DNA controllable peroxidase mimetic activity of $\mathrm{MoS}_{2}$ nanosheets for constructing a robust colorimetric biosensor. Nanoscale 2020, 12, 19420-19428. [CrossRef]

75. Lu, L.; Ge, Y.; Wang, X.; Lu, Z.; Wang, T.; Zhang, H.; Du, S. Rapid and sensitive multimode detection of Salmonella typhimurium based on the photothermal effect and peroxidase-like activity of $\mathrm{MoS}_{2} @$ Au nanocomposite. Sens. Actuators B Chem. 2021, 326, 128807. [CrossRef] 
76. Zhang, S.; Chen, Y.; Huang, Y.; Dai, H.; Lin, Y. Design and application of proximity hybridization-based multiple stimuliresponsive immunosensing platform for ovarian cancer biomarker detection. Biosens. Bioelectron. 2020, 159, 112201. [CrossRef]

77. Wang, X.; Wu, Q.; Jiang, K.; Wang, C.; Zhang, C. One-step synthesis of water-soluble and highly fluorescent MoS $_{2}$ quantum dots for detection of hydrogen peroxide and glucose. Sens. Actuators B Chem. 2017, 252, 183-190. [CrossRef]

78. Sreeramareddygari, M.; Somasundrum, M.; Surareungchai, W. In situ polymerization and covalent functionalisation of trithiocyanuric acid by $\mathrm{MoS}_{2}$ nanosheets resulting in a novel nanozyme with enhanced peroxidase activity. New J. Chem. 2020, 44 , 5809-5818. [CrossRef]

79. Dong, W.; Chen, G.; Hu, X.; Zhang, X.; Shi, W.; Fu, Z. Molybdenum disulfides nanoflowers anchoring iron-based metal organic framework: A synergetic catalyst with superior peroxidase-mimicking activity for biosensing. Sens. Actuators B Chem. 2020, 305, 127530. [CrossRef]

80. Khataee, A.; Haddad Irani-nezhad, M.; Hassanzadeh, J. Improved peroxidase mimetic activity of a mixture of WS $\mathrm{W}_{2}$ nanosheets and silver nanoclusters for chemiluminescent quantification of $\mathrm{H}_{2} \mathrm{O}_{2}$ and glucose. Microchim. Acta 2018, 185, 190. [CrossRef] [PubMed]

81. Huang, L.; Zhu, W.; Zhang, W.; Chen, K.; Wang, J.; Wang, R.; Yang, Q.; Hu, N.; Suo, Y.; Wang, J. Layered vanadium(IV) disulfide nanosheets as a peroxidase-like nanozyme for colorimetric detection of glucose. Microchim. Acta 2018, 185, 7. [CrossRef] [PubMed]

82. Lin, T.; Zhong, L.; Chen, H.; Li, Z.; Song, Z.; Guo, L.; Fu, F. A sensitive colorimetric assay for cholesterol based on the peroxidaselike activity of $\mathrm{MoS}_{2}$ nanosheets. Microchim. Acta 2017, 184, 1233-1237. [CrossRef]

83. Ma, D.; Yu, J.; Yin, W.; Zhang, X.; Mei, L.; Zu, Y.; An, L.; Gu, Z. Synthesis of Surface-Modification-Oriented Nanosized Molybdenum Disulfide with High Peroxidase-Like Catalytic Activity for $\mathrm{H}_{2} \mathrm{O}_{2}$ and Cholesterol Detection. Chem. A Eur. J. 2018, 24, 15868-15878. [CrossRef]

84. Nikfarjam, N.; Ghomi, M.; Agarwal, T.; Hassanpour, M.; Sharifi, E.; Khorsandi, D.; Ali Khan, M.; Rossi, F.; Rossetti, A.; Nazarzadeh Zare, E.; et al. Antimicrobial Ionic Liquid-Based Materials for Biomedical Applications. Adv. Funct. Mater. 2021, 31, 2104148. [CrossRef]

85. Tan, S.-A.; Agarwal, T.; Kar, S.; Borrelli, M.R.; Maiti, T.K.; Makvandi, P. A progressive review on paper-based bacterial colorimetric detection and antimicrobial susceptibility testing. In Food, Medical, and Environmental Applications of Polysaccharides; Pal, K., Banerjee, I., Sarkar, P., Bit, A., Kim, D., Anis, A., Maji, S., Eds.; Elsevier: Amsterdam, The Netherlands, 2021; pp. 687-718. ISBN 978-0-12-819239-9.

86. Agarwal, T.; Tan, S.-A.; Onesto, V.; Law, J.X.; Agrawal, G.; Pal, S.; Lim, W.L.; Sharifi, E.; Moghaddam, F.D.; Maiti, T.K. Engineered herbal scaffolds for tissue repair and regeneration: Recent trends and technologies. Biomed. Eng. Adv. 2021, 2, 100015. [CrossRef]

87. Huang, X.-W.; Wei, J.-J.; Liu, T.; Zhang, X.-L.; Bai, S.-M.; Yang, H.-H. Silk fibroin-assisted exfoliation and functionalization of transition metal dichalcogenide nanosheets for antibacterial wound dressings. Nanoscale 2017, 9, 17193-17198. [CrossRef]

88. Ma, D.; Xie, C.; Wang, T.; Mei, L.; Zhang, X.; Guo, Z.; Yin, W. Liquid-Phase Exfoliation and Functionalization of MoS 2 Nanosheets for Effective Antibacterial Application. ChemBioChem 2020, 21, 2373-2380. [CrossRef] [PubMed]

89. Niu, J.; Sun, Y.; Wang, F.; Zhao, C.; Ren, J.; Qu, X. Photomodulated Nanozyme Used for a Gram-Selective Antimicrobial. Chem. Mater. 2018, 30, 7027-7033. [CrossRef]

90. Yin, W.; Yu, J.; Lv, F.; Yan, L.; Zheng, L.R.; Gu, Z.; Zhao, Y. Functionalized Nano-MoS 2 with Peroxidase Catalytic and Near-Infrared Photothermal Activities for Safe and Synergetic Wound Antibacterial Applications. ACS Nano 2016, 10, 11000-11011. [CrossRef] [PubMed]

91. Liu, Y.; Lin, A.; Liu, J.; Chen, X.; Zhu, X.; Gong, Y.; Yuan, G.; Chen, L.; Liu, J. Enzyme-Responsive Mesoporous Ruthenium for Combined Chemo-Photothermal Therapy of Drug-Resistant Bacteria. ACS Appl. Mater. Interfaces 2019, 11, 26590-26606. [CrossRef]

92. Makvandi, P.; Baghbantaraghdari, Z.; Zhou, W.; Zhang, Y.; Manchanda, R.; Agarwal, T.; Wu, A.; Maiti, T.K.; Varma, R.S.; Smith, B.R. Gum polysaccharide/nanometal hybrid biocomposites in cancer diagnosis and therapy. Biotechnol. Adv. 2021, 48, 107711. [CrossRef] [PubMed]

93. Ma, J.; Qiu, J.; Wang, S. Nanozymes for Catalytic Cancer Immunotherapy. ACS Appl. Nano Mater. 2020, 3, 4925-4943. [CrossRef]

94. Li, Y.; Jia, R.; Lin, H.; Sun, X.; Qu, F. Synthesis of $\mathrm{MoSe}_{2} / \mathrm{CoSe}_{2}$ Nanosheets for NIR-Enhanced Chemodynamic Therapy via Synergistic In-Situ $\mathrm{H}_{2} \mathrm{O}_{2}$ Production and Activation. Adv. Funct. Mater. 2021, 31, 2008420. [CrossRef]

95. Mei, L.; Ma, D.; Gao, Q.; Zhang, X.; Fu, W.; Dong, X.; Xing, G.; Yin, W.; Gu, Z.; Zhao, Y. Glucose-responsive cascaded nanocatalytic reactor with self-modulation of the tumor microenvironment for enhanced chemo-catalytic therapy. Mater. Horizons 2020, 7, 1834-1844. [CrossRef]

96. Jiang, H.; Du, Y.; Chen, L.; Qian, M.; Yang, Y.; Huo, T.; Yan, X.; Ye, T.; Han, B.; Wang, Y.; et al. Multimodal theranostics augmented by transmembrane polymer-sealed nano-enzymatic porous $\mathrm{MoS}_{2}$ nanoflowers. Int. J. Pharm. 2020, 586, 119606. [CrossRef]

97. Maji, S.K.; Yu, S.; Chung, K.; Sekkarapatti Ramasamy, M.; Lim, J.W.; Wang, J.; Lee, H.; Kim, D.H. Synergistic Nanozymetic Activity of Hybrid Gold Bipyramid-Molybdenum Disulfide Core@Shell Nanostructures for Two-Photon Imaging and Anticancer Therapy. ACS Appl. Mater. Interfaces 2018, 10, 42068-42076. [CrossRef] [PubMed]

98. Yim, D.; Lee, D.-E.; So, Y.; Choi, C.; Son, W.; Jang, K.; Yang, C.-S.; Kim, J.-H. Sustainable Nanosheet Antioxidants for Sepsis Therapy via Scavenging Intracellular Reactive Oxygen and Nitrogen Species. ACS Nano 2020, 14, 10324-10336. [CrossRef]

99. Chen, T.; Zou, H.; Wu, X.; Liu, C.; Situ, B.; Zheng, L.; Yang, G. Nanozymatic Antioxidant System Based on MoS 2 Nanosheets. ACS Appl. Mater. Interfaces 2018, 10, 12453-12462. [CrossRef] [PubMed] 
100. Chen, T.; Zou, H.; Wu, X.; Chen, Y.; Situ, B.; Zheng, L.; Yang, G. Fullerene-like $\mathrm{MoS}_{2}$ Nanoparticles as Cascade Catalysts Improving Lubricant and Antioxidant Abilities of Artificial Synovial Fluid. ACS Biomater. Sci. Eng. 2019, 5, 3079-3088. [CrossRef]

101. Ren, C.; Li, D.; Zhou, Q.; Hu, X. Mitochondria-targeted TPP-MoS 2 with dual enzyme activity provides efficient neuroprotection through M1/M2 microglial polarization in an Alzheimer's disease model. Biomaterials 2020, 232, 119752. [CrossRef]

102. Wei, F.; Cui, X.; Wang, Z.; Dong, C.; Li, J.; Han, X. Recoverable peroxidase-like $\mathrm{Fe}_{3} \mathrm{O}_{4} @ \mathrm{MoS}_{2}$-Ag nanozyme with enhanced antibacterial ability. Chem. Eng. J. 2021, 408, 127240. [CrossRef] [PubMed]

103. Wu, J.; Wang, X.; Wang, Q.; Lou, Z.; Li, S.; Zhu, Y.; Qin, L.; Wei, H. Nanomaterials with enzyme-like characteristics (nanozymes): Next-generation artificial enzymes (II). Chem. Soc. Rev. 2019, 48, 1004-1076. [CrossRef]

104. Agarwal, V.; Chatterjee, K. Recent advances in the field of transition metal dichalcogenides for biomedical applications. Nanoscale 2018, 10, 16365-16397. [CrossRef]

105. Wang, Q.; Wei, H.; Zhang, Z.; Wang, E.; Dong, S. Nanozyme: An emerging alternative to natural enzyme for biosensing and immunoassay. TrAC Trends Anal. Chem. 2018, 105, 218-224. [CrossRef] 